\title{
Cyclopropanation Reactions of Halomethyllithium Carbenoids: A Computational Study of the Effects of Aggregation and Solvation
}

\author{
Lawrence M. Pratt* ${ }^{1}$ \\ Department of Chemistry \\ Fisk University \\ 1000 17th Ave. N. \\ Nashville, TN 37209 \\ lpratt@fisk.edu
}
Phương Thảo Thị Trần ${ }^{2}$ and Ngân Văn Nguỹên University of Pedagogy 280 An Duong Vuong District 5, Ho Chi Minh City, Vietnam

\section{B. Ramachandran $*^{3}$}

Chemistry, College of Engineering \& Science

Louisiana Tech University

Ruston, LA 71272

ramu@coes.latech.edu

E-mail: lpratt@fisk.edu

Current address: Gia Dinh High School, 195/29, Xo Viet Nghe Tinh Street, Binh Thanh District, Ho Chi Minh City, Vietnam.

3 E-mail: ramu@latech.edu 


\section{ABSTRACT}

Computational results are presented to support experimental evidence that cyclopropanation reactions of halomethyllithium carbenoids with alkenes occur through the concerted (methylene transfer) pathway rather than the alternate stepwise (carbometalation) pathway in non-polar and polar (THF, $\varepsilon=7.85$ ) media. These results complement and confirm the recent findings of Ke, Zhao, and Phillips (KZP) [J. Org. Chem. 2007, 72, 848] for ethylene in nonpolar and moderately polar (DME, $\varepsilon=4.34$ ) solvents. We also studied carbenoid reactions with 2,3-dimethyl-2butene. The explanation for the preference for the concerted pathway is provided by detailed examination of the reaction pathways of aggregated carbenoid species, which are the dominant reactive species in both polar and nonpolar solvents. The details of the syn- and antieliminations of lithium halide from the intermediate formed in the two-step mechanism with ethylene are also studied for the first time. Two stable dimeric structures were identified for the carbenoids and both have been studied. By explicit coordination of the monomeric and dimeric organolithium species to THF ligands, we also find that a clear preference for the concerted pathway is shown by both monomers and dimers in polar solvents, and solvent steric factors are dominant in determining the relative stabilities of the aggregates of the carbenoid species in THF solution.

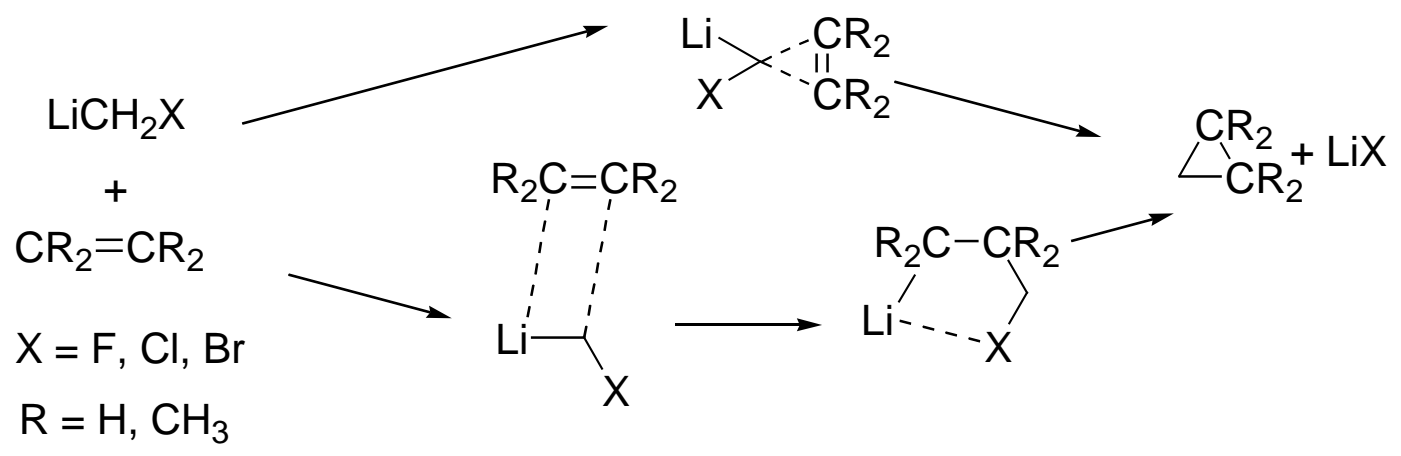




\section{Introduction}

This paper presents a detailed computational study of the reactions leading to the formation of cyclopropane rings by the insertion of a methylene group into a carbon-carbon double bond by halomethyllithium carbenoids $\mathrm{Li}_{-} \mathrm{CH}_{2}-\mathrm{X}$, where $\mathrm{X}=\mathrm{F}, \mathrm{Cl}$, and $\mathrm{Br}$. This work complements, and indeed confirms, many of the results recently reported by Ke, Zhao, and Phillips (KZP), ${ }^{1}$ but we also report several novel findings.

The widespread use of organometallic carbenoid species for synthesizing cyclopropane rings has a long history dating back at least to the 1958 report by Simmons and Smith [using the “Simmons-Smith" (SS) reagent $\left.\mathrm{IZnCH}_{2} \mathrm{I}\right]^{2}$ which was followed up by a more detailed report in

1959. ${ }^{3}$ On the basis of the stereospecificity of the reaction and other experimental observations, Simmons and Smith proposed a direct, or concerted, addition of $\mathrm{CH}_{2}$ to the double bond as the mechanism. A two-step mechanism involving carbometalation of the alkene, resulting in X$\left(\mathrm{CH}_{2}\right)_{3}-\mathrm{M}$ (where $\mathrm{X}$ is the halogen and $\mathrm{M}$ the metal) as intermediate, was proposed by Hoberg in 1962. ${ }^{4}$ Although Burger and Huisgen in $1970^{5}$ ruled out this mechanism for $\mathrm{X}=\mathrm{Cl}$ and $\mathrm{M}=\mathrm{Li}$ on the basis of the stereospecificity of the reaction, the collection of available experimental evidence is not conclusive. For example, Stiasny and Hoffmann ${ }^{6}$ studied intramolecular cyclopropanation reactions using bromolithium carbenoids and observed that the direct mechanism appears to have the lowest activation energy, proceeding quite readily even at extremely low temperatures $\left(-110^{\circ} \mathrm{C}\right)$. However, they also concluded that Lewis-acid assisted carbolithiation leading to cyclopropanation (the two-step mechanism) was competitive at higher temperatures $\left(-20^{\circ} \mathrm{C}\right.$ or higher). The possibility of free carbenes (rather than lithiocarbenoids) being responsible for the reaction has been ruled out by the complete absence of hydrocarbon isomerization products in these experiments. 
One of the first computational studies of the reactions considered here appear to be that

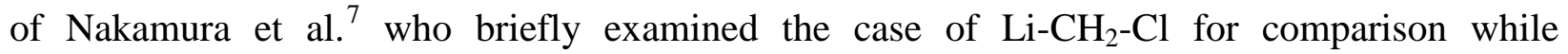
conducting a study of the SS reactions. Based on the Born-Oppenheimer (or classical) energy barrier heights of gas phase (or nonpolar solvent) reactions involving monomeric carbenoid species at the B3LYP/6-31G(d) level, Nakamura et al. concluded that no preference exists between the two pathways for the case of $\mathrm{Li}$ (in contrast, the SS reaction showed a clear preference for the concerted mechanism). Hermann et al. studied the concerted pathway only, in a study of the influence of leaving groups $(\mathrm{X}=\mathrm{F}, \mathrm{Cl}, \mathrm{Br}$, I, and $\mathrm{OH}) .{ }^{8}$ The most recent and most detailed study to date, and the only one to consider the influence of aggregates and explicit solvation, is that of $\mathrm{KZP}^{1}$ in which $\mathrm{X}=\mathrm{F}$ and $\mathrm{OH}$ are studied at the B3LYP/6-311G $(d, p)$ level of theory. That paper is part of a long series of outstanding computational investigations of metalocarbenoid-mediated cyclopropanation reactions from Phillips and coworkers. ${ }^{9,10,11,12,13}$ In this paper, we present a detailed study of the reactions of halomethyllithium species with ethylene and examine the relative viability of the two reaction pathways for $\mathrm{X}=\mathrm{F}, \mathrm{Cl}$, and $\mathrm{Br}$, at HF, B3LYP, and MP2 levels of theory using the $6-31+G(d)$ basis set. Many aspects of our work complement and confirm the results of KZP but several aspects are also novel and are summarized towards the end of this Section. It is important to note that although the fluoro substituent is easier to handle computationally compared to the chloro and bromo substituents, the chemistry of fluoro compounds can be quite different. An investigation of the FritschButtenberg-Wiechell (FBW) rearrangement of lithium vinylidine carbenoids is currently in progress in Pratt's laboratory. Preliminary results show that the fluoro substituent affects not only the barrier height, but in some cases, even the mechanism of rearrangement. ${ }^{14}$ This can be attributed to not only the greater electronegativity of fluorine, but the acid-base properties as 
well. Fluoride ion is a hard base, while chloride and bromide ions are comparatively soft bases, and bind less strongly with the hard lithium cation and proton. Thus, fluoromethyllithium reactions may parallel those of the more synthetically useful chloro- and bromomethyllithium carbenoids in some cases, but we cannot generally expect to find similar barrier heights or even the same mechanism.

Lithium carbenoids are important reagents in synthetic organic chemistry. In addition to halomethyllithiums, carbene-like reactivity has been observed in 1-halo-1-lithioalkenes and $\alpha$ lithioethers, particularly oxiranyllithium compounds. As carbene-like species, lithium carbenoids undergo a variety of single and double bond insertion reactions. Nucleophilic reactions of related oxiranyllithium carbenoids are also known. ${ }^{15,16,17,18}$ The chemistry of organolithium compounds in general is quite complex because of their tendency to form aggregates in solution. The reactivity and the thermochemistry often depend sensitively on the aggregation state and solvation effects. ${ }^{19,20}$ The precise nature of the reactive species is difficult to characterize experimentally and, therefore, computational investigations are necessary to further our understanding. However, computational investigations of organolithium chemistry also present many challenges. Semi-empirical methods are poorly parameterized for lithium compounds. ${ }^{21}$ Moreover, electron correlation effects appear to be quite important in the intermolecular interactions in these species, which means that relatively high levels of theory are necessary. Ethereal solvents like THF bind quite strongly as ligands to the lithium atoms, forming a "supermolecule" consisting of the organolithium molecule and its first solvation sphere. ${ }^{22,23}$ Steric and electronic effects of the coordinated ligands are important and the steric effects, in particular, cannot be adequately represented by continuum solvation models. 
The present work studies the cyclopropanation reactions of $\left(\mathrm{Li}^{-} \mathrm{CH}_{2}-\mathrm{X}\right)_{n}(n=1,2,4)$ where $\mathrm{X}=\mathrm{F}, \mathrm{Cl}$, or $\mathrm{Br}$, with ethylene and $\left(\mathrm{Li}^{-} \mathrm{CH}_{2}-\mathrm{X}\right)_{2}$ with 2,3-dimethyl-2-butene (DMB), using Hartree-Fock, hybrid density functional theory (B3LYP), and second order Møller-Plesset perturbation theory (MP2), all using the $6-31+G(d)$ basis set. Reactions of the monomers and dimers with ethylene are modeled both in the gas phase and in THF solution. Gas phase reactions provide a standard against which to gauge the influence of solvation on reaction energetics, but the results should also be reasonable approximations to non-coordinating solvent environments which were employed in the experiments of Burger and Huisgen ${ }^{5}$ and those of Stiasni and Hoffmann. ${ }^{6}$ We consider single-step insertion of the methylene group into the ethylene double bond as well as the stepwise pathways in which a 3-halo-1-propyllithium is first formed which then undergoes a syn or anti elimination of the lithium halide to yield the cyclopropane ring. Analogous reactions of the dimeric species are also studied in detail along with a brief examination of the direct insertion mechanism of the tetramer. The reactions of (Li$\left.\mathrm{CH}_{2}-\mathrm{X}\right)_{2}$ with dimethylbutene are studied in the gas phase so as to confirm that the trends emerging from the detailed studies on ethylene are also observed for other alkene species.

Given the uncertainties as to the reaction mechanisms, Intrinsic Reaction Coordinate (IRC) calculations ${ }^{24,25}$ have been performed to verify whether the transition states identified are, in fact, the ones that connect the reactants to the intermediates or products. Finally, these reactions are also modeled in THF solution, represented by THF molecules coordinated to the lithium atoms. In addition to full optimization of all reactants, products, and transition state (TS) structures at the HF, B3LYP, and MP2 levels of theory, we also compare energies (minima as well as saddle-points) from single point MP2 calculations at B3LYP-optimized geometries (MP2//B3LYP) to evaluate the reliability of the hybrid DFT approach to the study of these 
reactions. A few stationary points along the gas phase reaction paths have also been examined at the $\operatorname{CCSD}(\mathrm{T}) / 6-31+\mathrm{G}(\mathrm{d})$ level of theory.

Some of novel findings reported in the current work are the following:

1. First detailed study of cyclopropanation reactions of $\left(\mathrm{Li}^{-} \mathrm{CH}_{2}-\mathrm{X}\right)_{n},(n>1)$ for $\mathrm{X}=\mathrm{Cl}$ and $\mathrm{Br}$, which are more widely used for synthetic work than the $\mathrm{X}=\mathrm{F}$ case studied by KZP.

2. The first detailed study of the reactions of $\left(\mathrm{Li}-\mathrm{CH}_{2}-\mathrm{X}\right)_{2}$ with dimethylbutene.

3. First study of the details of the second step of the two-step process proposed by Hoberg. ${ }^{4}$ We find that, contrary to earlier assumptions, the reaction barriers for the eliminiation of LiX from the intermediate 1-halo-3-propyllithiums are comparable to those of the first step.

4. The MP2/6-31+G(d) level IRC calculations reveal that a pre-reactive complex is formed only in the case of the stepwise (carbometalation) mechanism for monomers and dimers.

5. Study of the reactions in THF solvent reveal interesting differences in the properties of the molecules from the dimethyl ether (DME) environment studied by KZP.

6. Comparison of MP2 and MP2//B3LYP (i.e., MP2 single point calculation at B3LYP geometry) energies for the relevant species involved in the various pathways reveal that B3LYP geometries are quite close to the MP2 ones in the gas phase, but there are important differences between the THF-solvated structures predicted by the two methods.

7. In addition to the dimeric species studied by KZP (labeled $\mathbf{6}$ below), the reactions of a constitutional isomer (labeled $\mathbf{7}$ below) are also examined, and the latter is found to provide a lower energy pathway to products. 
8. The stability of solvated tetramers relative to the solvated dimers is examined. We conclude that dimers are the predominant aggregated species of $\mathrm{LiCH}_{2} \mathrm{X}$ in THF solvent.

9. Comparison of continuum solvation (PCM) results and explicit solvation for the tetramers reveal that the relative instability of solvated tetramers (see item 8 above) is primarily due to steric effects in the primary solvation sphere, not electrostatic effects in a polar solvent.

\section{Reaction Pathways and Computational Methods}

\section{A. Reaction Pathways}

As noted earlier, it has been proposed that cyclopropanation using halomethyllithium carbenoids proceed either by a direct insertion into the alkene C-C bond as shown in Eq. (1), or by a multi-step process in which a 3-halo-1-propyllithium intermediate is first formed as shown in Eq. (2).

$$
\begin{aligned}
& \mathrm{H}_{2} \mathrm{C}=\mathrm{CH}_{2}+\mathrm{Li}-\mathrm{CH}_{2}-\mathrm{X} \rightarrow \mathrm{TS} \mathbf{1} \rightarrow \text { cyclopropane }+\mathrm{LiX} \\
& \mathrm{H}_{2} \mathrm{C}=\mathrm{CH}_{2}+\mathrm{Li}-\mathrm{CH}_{2}-\mathrm{X} \rightarrow \text { complex } \mathbf{2}^{\prime} \rightarrow \text { TS } \mathbf{2} \rightarrow \underset{\mathbf{2 i}-\left(\mathrm{CH}_{2}\right)_{3}-\mathrm{X}}{ }
\end{aligned}
$$

The intermediate could then undergo a syn or anti elimination of the lithium halide, as shown in Eq. (3), to form cyclopropane.

$$
\underset{\mathbf{L}}{\mathrm{Li}-\left(\mathrm{CH}_{2}\right)_{3}-\mathrm{X}} \rightarrow \text { [TS } 4 \text { (anti) or } \mathbf{5} \text { (syn)] } \rightarrow \text { cyclopropane }+\mathrm{LiX}
$$

These reaction pathways, including the formation of the pre-reactive complex 2', were confirmed by IRC calculations at the MP2 level of theory in the gas phase.

Reactions of the dimeric species are expected to be analogous. Recently, we identified two distinct constitutional isomers for the dimeric species, ${ }^{26}$ denoted as 6 and 7, with structures shown below. 


$$
\begin{aligned}
& \left.\mathrm{H}_{2} \mathrm{C}=\mathrm{CH}_{2}+\left(\mathrm{Li}-\mathrm{CH}_{2}-\mathrm{X}\right)_{2} \rightarrow \text { [TS structure }\right] \rightarrow \text { cyclopropane }+\mathrm{LiX}+\mathrm{Li}-\mathrm{CH}_{2}-\mathrm{X} \\
& 6 \text { or } 7 \quad \text { TS } 8 \text { or TS } 9 \\
& \mathrm{H}_{2} \mathrm{C}=\mathrm{CH}_{2}+\left(\mathrm{Li}-\mathrm{CH}_{2}-\mathrm{X}\right)_{2} \rightarrow \text { complex } \mathbf{1 0}^{\prime} \text { or } \mathbf{1 1}^{\prime} \rightarrow \text { [TS structure] } \\
& 6 \text { or } 7 \quad \text { TS } 10 \text { or TS } 11 \\
& \rightarrow \mathrm{Li}-\left(\mathrm{CH}_{2}\right)_{3}-\mathrm{X}+\mathrm{Li}-\mathrm{CH}_{2}-\mathrm{X} \\
& 3
\end{aligned}
$$

As in the case of the monomers, the existence of the pre-reactive complexes in Eq. (5) were verified by IRC calculations at the MP2 level. The intermediate 3 formed in Eq. (5) reacts according to Eq. (3). The structural formulae of the important monomeric and dimeric species studied for the case of ethylene are summarized below.

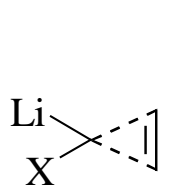

TS 1

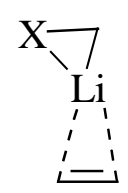

Precomplex 2'

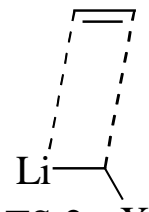

TS $2 \mathrm{X}$

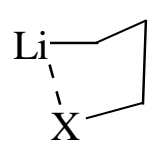

3

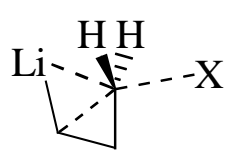

TS 4

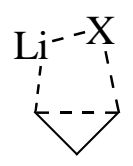

TS 5

$$
\stackrel{\mathrm{Li}}{\mathrm{L}}-\mathrm{X}-\mathrm{X}-\mathrm{Li}
$$

6<smiles>[X]C1[Al]2C=C[Al]1[Al]C2</smiles>

Precomplex 10'

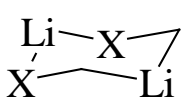

7

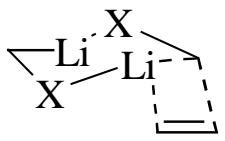

TS 10

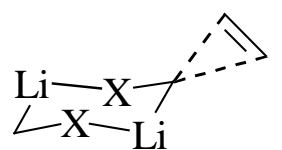

TS 8

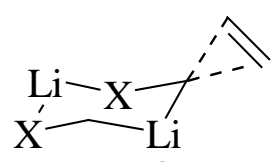

TS 9

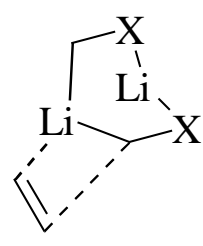

Precomplex 11'

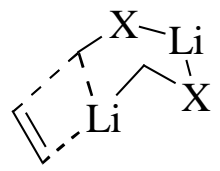

TS 11

The reactions of lithium carbenoids with 2,3-dimethyl-2-butene (DMB) proceed through similar mechanisms and involve similar intermediate and transition state structures.

\section{B. Computational Methods}

All geometry optimizations, TS structure searches, and frequency calculations were performed with the Gaussian 98 or Gaussian 03 programs. ${ }^{27}$ Transition state structures were 
located with either the QST3 method, or by further optimization of a previously located transition structure at a different level of theory using the Opt=TS keyword. Geometry optimizations were performed at the HF/6-31+G(d), B3LYP/6-31+G(d), and MP2/6-31+G(d) levels of theory for both the reactants and transition structures. MP2 single point energy calculations were performed at the B3LYP geometries to determine whether B3LYP generates satisfactory geometries at a fraction of the computational cost of full MP2 optimizations. Harmonic frequencies of the reactants and transition structures were calculated at the HF/6$31+G(d)$ level. Since cyclopropanation reactions are typically carried out at very low temperatures, free energy corrections were calculated at $173.15 \mathrm{~K}$ from these frequency calculations and added to the electronic energies at each level of theory, in order to obtain approximate free energies of each reactant and TS structure.

Intrinsic reaction coordinate (IRC) calculations were performed using the algorithms of Gonzalez and Schlegel ${ }^{28}$ as implemented in Gaussian 03. The reaction coordinate is expressed as a mass-weighted distance along the path of steepest descent from its origin at the saddle point towards the reactants (negative values) and towards products (positive values).

Solvent effects were modeled by placing explicit THF ligands on the lithium atoms. Two ligands were used for each carbenoid monomer, and either three or four ligands for the dimers. Special care is taken to ensure consistent handling of standard states. ${ }^{29,30}$ Specifically, a correction term $R T \ln \left(c^{\circ} R T / P^{\circ}\right)$ must be added per mole of each species in the reaction under consideration, which represents the change in free energy involved in compressing the system from standard pressure $P^{\circ}$ (or a concentration of $P^{\circ} / R T$ ) used in gas phase calculations to the standard concentration of $c^{\circ}=1 \mathrm{~mol} / \mathrm{L}$ commonly used for solutions. This term is numerically equal to $+0.9131 \mathrm{kcal} / \mathrm{mol}$ at $173.15 \mathrm{~K}$ and, while it cancels from both sides when the net change 
in the number of moles due to reaction $\Delta n=0$, it is a non-negligible correction in cases where $\Delta n$ $\neq 0$. Yet another correction is required for cases where a THF ligand dissociates, as in

$$
\mathrm{RLi} \cdot n \mathrm{THF} \rightleftarrows \mathrm{RLi} \cdot m \mathrm{THF}+(n-m) \mathrm{THF}
$$

for which

$$
\Delta G^{\circ}=-R T \ln \frac{[\mathrm{RLi} \cdot m \mathrm{THF}]}{[\mathrm{RLi} \cdot n \mathrm{THF}]}-(n-m) R T \ln \frac{[\mathrm{THF}]}{c^{\circ}} .
$$

Since the concentration of pure THF is different from the standard concentration $c^{\circ}$, it was evaluated from its molar volume at $1 \mathrm{~atm}$ and $173.15 \mathrm{~K}$ using the empirical expression provided by Govender et al. ${ }^{31}$ and incorporated into the second term of Eq. (6). Numerically, this correction to $\Delta G^{\circ}$ amounts to $-0.9014 \mathrm{kcal}$ per mole of free THF at $173.15 \mathrm{~K}$. This approach to modeling solvation effects on organolithium compounds has been used in other studies,,$^{30,32,33,34,35,36,37}$ and has been found to give results in agreement with available experimental results.

\section{Results and Discussion}

\section{A. Reactions of gas phase monomers with ethylene}

The MP2/6-31+G(d) level IRC's for the reactions of the gas phase monomers given in Eqs. (1) and (2) are presented in Figure 1, for the case of $X=B r$. The solid symbols connected by the solid line represents the IRC of the concerted mechanism (Eq. 1). The point A represents the farthest point along the IRC for which structures could be converged, starting from the transition state TS 1 and proceeding towards the reactants. The empty symbols connected by the solid line represents the IRC for the first step of the stepwise mechanism (Eq. 2), and the point D represents the minimum value of the IRC for which structures could be converged, starting from the transition state TS 2 and proceeding towards the reactants. The nature of this IRC suggested 
that a pre-reactive complex $\mathbf{2}^{\prime}$ is being formed. The optimized structure of this complex is represented by the point $\mathrm{C}$, which is placed schematically on the IRC (i.e., the value of the reaction coordinate for this point is guided only by the physically reasonable expectation that the IRC should smoothly connect the point D to the reactants while passing through C). Spline interpolations connecting these calculated points to the asymptotic reactants in a physically reasonable manner are shown as dashed lines. The molecular structures corresponding to the labeled points are shown in Figure 2. We have examined and confirmed that the IRC's and structures for the cases $\mathrm{X}=\mathrm{F}$ and $\mathrm{Cl}$ are qualitatively similar.

\section{*** Suggested location for Figs. 1 and $2 * * *$}

We first consider the concerted mechanism via TS 1. It is clear from the IRC shown in Figure 1 and the structures shown on the top row of Figure 2 that the reaction is initiated by the interaction of the methylene group with the $\pi$-bond of the alkene, leading to the direct insertion of the $\mathrm{CH}_{2}$ group into the ethylene double bond, resulting in the formation of the cyclopropane ring. The essential stages of the stepwise mechanism are quite different. This pathway starts by the interaction of the lithium with the $\pi$-bond of the alkene, leading to the formation of a prereactive complex $\mathbf{2}^{\prime}$. A rearrangement of this complex leads to the structure $\mathrm{D}$, then to the fourmembered ring structure of TS 2 and eventually the intermediate 3.

The zero-point inclusive relative (with respect to reactants) energies at $0 \mathrm{~K}, \Delta U_{0}^{\circ}$, and Gibbs free energy changes at $173.15 \mathrm{~K}$ and standard pressure, $\Delta G^{\circ}$, for the processes summarized in Eqs. 1 and 2 are given in Table 1 for all three halogens and the different levels of theory examined. We have omitted the Hartree-Fock results in the Table. Because of the correction term mentioned in the paragraph above Eq. (6), the $\Delta G^{\circ}$ for the formation of TS $\mathbf{1}$, pre-reactive complex 2', and TS 2 will each be lowered by $0.91 \mathrm{kcal} / \mathrm{mol}$ in non-polar solvents. 
*** Suggested location for Table 1

The zero-point-energy inclusive reaction barrier $\left(\Delta U_{0}^{\ddagger}\right)$ of $\mathrm{KZP}^{1}[\mathrm{~B} 3 \mathrm{LYP} / 6-311 \mathrm{G}(d, p)]$ to form TS $1(\mathrm{X}=\mathrm{F})$ is $7.8 \mathrm{kcal} / \mathrm{mol}$, compared to our own B3LYP/6-31+G(d) result of $6.47 \mathrm{kcal} / \mathrm{mol}$. For TS 2, KZP report a $\Delta U_{0}^{\ddagger}$ of $4.3 \mathrm{kcal} / \mathrm{mol}$, which compares well with the $4.11 \mathrm{kcal} / \mathrm{mol}$ reported in Table 1 . The $\Delta U_{0}^{\circ}$ for the pre-reactive complex C is $-8.2 \mathrm{kcal} / \mathrm{mol}$ in Ref. 1 , and $-8.60 \mathrm{kcal} / \mathrm{mol}$ in our work. The $\Delta U_{0}^{\circ}$ for the formation of cyclopropane and the intermediate 3 are $-60.3 \mathrm{kcal} / \mathrm{mol}$ and $-23.2 \mathrm{kcal} / \mathrm{mol}$, respectively in Ref. 1 , compared to -53.39 and $-23.07 \mathrm{kcal} / \mathrm{mol}$, respectively, in our work. We conclude that the methods and basis sets used in this paper are of sufficiently high quality to yield qualitatively correct results while remaining small enough for MP2 level calculations on the aggregates of the $\mathrm{X}=\mathrm{Cl}$ and $\mathrm{Br}$ cases. Table 1 also shows that the MP2//B3LYP energies are within $\pm 1 \mathrm{kcal} / \mathrm{mol}$ to the MP2 results, indicating that B3LYP geometries are consistently of MP2 quality in this case. We will see below that there are some instances where this is not the case.

The IRC's in Figure 1 and the results tabulated in Table 1 show that the $\Delta U_{0}^{\ddagger}$ for the formation of TS $\mathbf{1}$ and TS $\mathbf{2}$ are comparable for all three halogens. As mentioned in the Introduction, this is contrary to experimental evidence which indicates a clear preference for the concerted pathway. Examination of aggregated structures, first reported by KZP in Ref. 1 and which we will present shortly, yields results that support existing experimental evidence.

In contrast to KZP's Figure 1, we were not able to identify a pre- reactive complex on the IRC for the concerted mechanism, using B3LYP or MP2. As indicated by Figure 1, the IRC for the concerted reaction rapidly approaches its asymptotic value and shows no indication of dipping below that value. We could not force the IRC calculation beyond the point labeled A in 
Figure 1, presumably because the energy landscape becomes very flat quite rapidly. In sharp contrast, the IRC for the carbometalation mechanism could be extended beyond the point $\mathrm{D}$ towards $\mathrm{C}$ with no difficulty.

To the best of our knowledge, there has been no study of the details of the second step of the two-step mechanism in which the LiX is eliminated, leaving behind the cyclopropane ring. As shown in Eq. (3), the second step could occur in either an anti geometry, similar to an $\mathrm{S}_{\mathrm{N}} 2$ reaction (TS 4), or in a syn fashion (TS 5), with the lithium and halide ions eliminating from the same side of the intermediate. As a representative of the methods and molecules studied, we show the B3LYP/6-31+G(d) IRC's in Figure 3 for $\mathrm{LiCH}_{2} \mathrm{Cl}$. The relevant structures are presented in Figure 4. For anti elimination (TS 4), we encountered convergence difficulties beyond either extremes of the IRC shown. Comparing the structures in panels F, TS2, and G of Figure 4, it appears that anti-elimination results in a cyclopropane ring that continues to interact with the lithium cation as the chloride ion is leaving. The $\Delta U_{0}^{\ddagger}$ and $\Delta G^{\ddagger}$ for the anti and syn eliminations are summarized in Table 2.

\section{*** Suggested location for Figs. 3 and $4 * * *$}

\section{*** Suggested location for Table $2 * * *$}

There are significant differences between the $\Delta G^{\ddagger}$ for the different halogen species for the second step of the two-step mechanism. Focusing on MP2 and MP2//B3LYP energies, there appears to be a clear preference for syn elimination in the case of $X=F$, a preference for the anti elimination in the case of $\mathrm{X}=\mathrm{Br}$, and no clear preference in the case of $\mathrm{X}=\mathrm{Cl}$. These results can be rationalized on the basis of Lewis acid-base interactions. The hard fluoride ion binds strongly to the hard lithium ion in the transition state, thus favoring syn elimination. In contrast, 
the bromo carbenoid favors a backside, $\mathrm{S}_{\mathrm{N}} 2$-like elimination mechanism. Once again, all free energy values will decrease by $0.91 \mathrm{kcal} / \mathrm{mol}$ in non-polar solvent environment.

\section{B. Reactions of gas phase dimers with ethylene}

Our previous work suggested that halomethyllithium carbenoids are gas phase dimers, and may be largely dimeric in ethereal solvents. ${ }^{38}$ As noted earlier, we have identified two distinct constitutional isomers for the dimeric species. ${ }^{26}$ The dimerization free energies are found to be substantial, as shown in Table 3. Since both dimeric species are of comparable stability, we consider the reactions of both species.

\section{*** Suggested location for Table $3 * * *$}

The MP2/6-31+G(d) IRC's for the concerted and stepwise reactions of $6(\mathrm{X}=\mathrm{Br})$ are shown in Figure 5(a), and the analogous IRC's for $7(X=B r)$ are shown in Figure 5(b). The structures corresponding to the labeled points in Figure 5(a) are presented in Figure 6, and those for Figure 5(b) are in Figure 7. The pre-reactive complex leading to TS $\mathbf{1 0}$ is designated as $\mathbf{1 0}$ and that leading to TS $\mathbf{1 1}$ as $\mathbf{1 1}$ ', both denoted by the points $C$ on the IRC's in the panels of Fig. 5. Table 4 summarizes the $\Delta U_{0}^{\circ}$ and $\Delta G^{\circ}$ data.

\section{*** Suggested location for Figs. 5, 6, and $7 * * *$ *** Suggested location for Table $4 * * *$}

The two panels of Figure 5 immediately reveal that the reaction barrier for the stepwise mechanism is substantially higher than that for the direct insertion pathway for both dimeric species. The $\Delta U_{0}^{\circ}$ and $\Delta G^{\circ}$ data in Table 4 reveal that this is true for all three halomethyllithium species studied. Recall that in the case of gas-phase monomers, there was no clear preference between the direct and stepwise mechanisms on the basis of barrier heights (Figure 1 and Table 
1). Since the dimers are markedly more stable than the monomeric species (Table 3), they are among the dominant reactive species present. Therefore, it appears that one of the reasons computational studies prior to those of KZP failed to establish the preference for the concerted pathway over the carbometalation pathway for cyclopropanation reactions of halomethyllithiums was because they did not consider dimeric species.

Tables 1-4 also contain the $\Delta U_{0}^{\circ}$ values calculated at $\operatorname{CCSD}(\mathrm{T}) / 6-31+\mathrm{G}(d)$ level of theory at MP2 geometries. There are no qualitative differences between the MP2 and CCSD(T) results in any case and, in many cases, the calculated energy differences are comparable. In Table 1, CCSD(T)//MP2 energy barriers for TS2 are higher than those for TS1, indicating a slight preference for the concerted mechanism even in the case of the monomeric $\mathrm{LiCH}_{2} \mathrm{X}$. A notable difference between the MP2 and $\operatorname{CCSD}(\mathrm{T})$ results are in the $\Delta U_{0}^{\circ}$ for the formation of the prereactive complex of dimer 7 [Table $4, \mathbf{1 1}^{\prime}$ (from 7)] for $\mathrm{X}=\mathrm{Br}$. We are unable to explain the nearly $9 \mathrm{kcal} / \mathrm{mol}$ difference between the MP2 and $\operatorname{CCSD}(\mathrm{T})$ results in this case, especially given that the two sets of results are comparable for the formation of $\mathbf{1 0}^{\prime}$ (from $\mathbf{6}$ ) for $\mathrm{X}=\mathrm{Br}$ and for the other halogens.

The data in Table 4 show that the highest barrier height is found in the reaction of the chloromethyllithium dimers. Comparison of the bromo- and chloromethyllithium reactions suggests that the breaking of the weaker $\mathrm{C}-\mathrm{Br}$ bond is significant in the transition state. However, the C-F bond is even stronger than the C-Cl bond, so fluoromethyllithium would be expected to have the highest barrier height based on bond strengths. Closer examination of the transition state geometries shows the product to be a carbenoid-LiX mixed aggregate. The strong hard acid-hard base interaction between lithium and fluorine apparently stabilizes the transition state leading to that product. 


\section{Reactions of THF solvated monomers with ethylene}

The primary solvation shell of lithium carbenoids in THF appears to consist of two THF ligands strongly bound to the Li. Steric factors inhibit the coordination by additional solvent molecules. These bis-THF solvated carbenoid monomers were found to undergo similar reactions to those in the gas phase. The direct insertion is initiated by the interaction of the methylene group with the alkene double bond, leading to TS 1·2THF.

Unlike the gas-phase carbometalation reactions and the calculations of KZP with coordinated DME ligands, we were unable to identify a pre-reactive complex for the bis-THF solvated monomers. An intermediate similar to the gas phase pre-reactive complex $\mathbf{2}^{\prime}$ in Figure 1 was found for the monosolvated case:

$$
\mathrm{H}_{2} \mathrm{C}=\mathrm{CH}_{2}+\mathrm{LiCH}_{2} \mathrm{Cl} \cdot 1 \mathrm{THF} \rightarrow \mathbf{2}^{\prime} \cdot 1 \mathrm{THF}(\mathrm{X}=\mathrm{Cl}) ; \Delta U_{0, \mathrm{~B} 3 \mathrm{LYP}}^{\circ}=-2.90 \mathrm{kcal} / \mathrm{mol}
$$

However, relative to ethylene and $\mathrm{LiCH}_{2} \mathrm{Cl} \cdot 2 \mathrm{THF}$, the formation of the monosolvated complex is energetically unfavorable:

$$
\mathrm{H}_{2} \mathrm{C}=\mathrm{CH}_{2}+\mathrm{LiCH}_{2} \mathrm{X} \cdot 2 \mathrm{THF} \rightarrow 2^{\prime} \cdot 1 \mathrm{THF}(\mathrm{X}=\mathrm{Cl})+\mathrm{THF} ; \Delta U_{0, \mathrm{~B} \text { LYP }}^{\circ}=8.55 \mathrm{kcal} / \mathrm{mol}
$$

The formation of the pre-reactive complex is also unfavorable on the basis of free energy change, which is found to be $\Delta G^{\circ}=+4.13 \mathrm{kcal} / \mathrm{mol}$ for Eq. (7) and $+9.90 \mathrm{kcal} / \mathrm{mol}$ for Eq. (8) at B3LYP/6-31+G(d) level.

KZP report a weakly bound $\left(\Delta U_{0, \mathrm{~B} 3 \mathrm{LYP} / 6-311 \mathrm{G}(d, p)}^{\circ}=-1.4 \mathrm{kcal} / \mathrm{mol}\right)$ complex between $\mathrm{LiCH}_{2} \mathrm{~F} \cdot 2 \mathrm{DME}$ and ethylene, but the alkene is more than $5 \AA$ away from the solvated species (Figure 4 of Ref. 1). We searched for, but could not find, a similar complex for $\mathrm{LiCH}_{2} \mathrm{X} \cdot 2 \mathrm{THF}$ at the DFT or MP2 levels of theory. It appears that the more rigid structure of the THF ligands and their stronger interaction with the $\mathrm{Li}$ atom introduces greater steric and energetic constraints 
that are not present in the DME solvent. In spite of the absence of a stable pre-reactive complex in the case of the bis-THF solvated monomers, the stepwise addition appears to follow the essential stages of the gas phase reaction, including the formation of the four-membered TS $2 \cdot 2 \mathrm{THF}$ leading to the intermediate $3 \cdot 2 \mathrm{THF}$.

The MP2/6-31+G(d) optimized TS structures for the concerted and stepwise insertions (TS 1.2THF and TS 2.2THF, respectively) and the intermediate 3.2THF are shown in Supporting Information. The related free energy data are summarized in Table 5.

\section{*** Suggested location for Table $5 * * *$}

Comparison of the MP2 and MP2//B3LYP results in Tables 1 and 5 show that, with the exception of $\mathrm{X}=\mathrm{Br}$, solvation has no significant effect on the $\Delta G^{\ddagger}$ for direct insertion while solvation increases the barrier heights for the stepwise reaction by 3 to $7 \mathrm{kcal} / \mathrm{mol}$. (The difference in the $\Delta G^{\ddagger}$ of TS 2 and TS 2.2THF are much larger at the B3LYP level of theory, ranging from 9 to $11 \mathrm{kcal} / \mathrm{mol}$ ). Unlike the gas phase, the concerted mechanism is preferred over the stepwise reaction of monomers when explicit THF solvation is considered. These observations are consistent with the trends in the energy barriers reported by KZP (Table 1 of Ref. 1) for the case of two coordinated dimethylether (DME) solvent molecules.

The effect of THF solvation on the next step in the stepwise mechanism, namely, the elimination of the lithium halide through syn or anti pathways, also appears to be quite significant as shown in Table 6. When compared to the gas phase (Table 2), THF solvation appears to uniformly lower the energy of TS $4 \cdot 2 \mathrm{THF}$ for anti elimination relative to the reactants while raising the energy of the transition state TS 5·2THF for syn elimination. This is likely a result of increased stability of the separated ions $\mathrm{X}^{-}$and $\mathrm{Li}^{+}$in the presence of a strongly coordinating polar solvent while the direct formation of LiX from TS $\mathbf{5}$ is more favorable in the 
gas phase. The structures of TS $4 \cdot 2 \mathrm{THF}$ and TS 5·2THF are shown in Supporting Information. Note that, as in the case of Table 2, Table 6 reports the energies of the transition states for anti and syn eliminations relative to the starting materials $\mathrm{H}_{2} \mathrm{C}=\mathrm{CH}_{2}+\mathrm{LiCH}_{2} \mathrm{X} \cdot 2 \mathrm{THF}$. The energetics relative to the reactive intermediate $3 \cdot 2 \mathrm{THF}$ is easily recovered by subtracting from these numbers the appropriate values given in Table 5 for the formation of $3 \cdot 2 \mathrm{THF}$. So, for example, the $\Delta U_{0, \mathrm{MP} 2}^{\ddagger}$ of TS $4 \cdot 2 \mathrm{THF}$ for $\mathrm{X}=\mathrm{Br}$ is $-3.43 \mathrm{kcal} / \mathrm{mol}$ relative to $\mathrm{H}_{2} \mathrm{C}=\mathrm{CH}_{2}+$ $\mathrm{LiCH}_{2} \mathrm{X} \cdot 2 \mathrm{THF}$ but $-3.43-(-18.26)=14.83 \mathrm{kcal} / \mathrm{mol}$ relative to $3 \cdot 2 \mathrm{THF}$.

\section{*** Suggested location of Table $6 * * *$}

Another aspect of Tables 5 and 6 deserves comment, namely, the rather large differences in the B3LYP and MP2 energy differences in the formation of TS 2·2THF and 3·2THF (Table 5), and the energy of TS $4 \cdot 2 \mathrm{THF}$ relative to the reactants (Table 6). In these cases, the MP2 and MP2//B3LYP results are reasonably close, indicating that the B3LYP geometries are close to those found by MP2, but the B3LYP functional yields a rather different energy.

As mentioned above, we also examined the reactions of monosolvated monomers in the case of $\mathrm{X}=\mathrm{Cl}$ at the B3LYP/6-31+G(d) level, including IRC calculations of reaction paths. Except for the discovery of the pre-reactive complex for the stepwise reaction (See Eq. 7), the results were qualitatively similar to those reported by KZP for X = F in DME, and the gas phase results reported above, in this work. Since the monosolvated monomers are unstable relative to the disolvated species (see Eq. 8), they are not discussed further. 


\section{Reactions of THF solvated dimers with ethylene}

The dimeric halomethyllithium carbenoids exist largely as the tetrasolvates in THF solution. ${ }^{38}$ On the other hand, dissociation to the trisolvated forms is reasonably facile. The $\Delta U_{0}^{\circ}$ and $\Delta G^{\circ}$ for the following equilibria at $173.15 \mathrm{~K}$ are summarized in Table 7 .

$$
\begin{gathered}
2 \mathrm{LiCH}_{2} \mathrm{X} \cdot 2 \mathrm{THF} \rightarrow\left(\mathrm{LiCH}_{2} \mathrm{X}\right)_{2} \bullet 4 \mathrm{THF} \\
\left(\mathrm{LiCH}_{2} \mathrm{X}\right)_{2} \bullet 4 \mathrm{THF} \rightarrow\left(\mathrm{LiCH}_{2} \mathrm{X}\right)_{2} \bullet 3 \mathrm{THF}+\mathrm{THF}
\end{gathered}
$$

\section{*** Suggested location of Table $7 * * *$}

The most striking aspects of Table 7 are the large differences between B3LYP and MP2 results and the less dramatic, but significant, differences between MP2 and MP2//B3LYP results. The B3LYP method yields qualitatively different results for the dimerization free energies, indicating that the trisolvated species are more stable. The appreciable differences between MP2 and MP2//B3LYP energies indicate non-negligible differences in the predicted equilibrium structures.

The following analysis is presented to substantiate the last statement. The three panels of Figure 8 show the equilibrium structures of $\mathbf{6} \cdot 4 \mathrm{THF}$ for $\mathrm{X}=\mathrm{F}$ obtained from (a) B3LYP/6$31+\mathrm{G}(\mathrm{d})$ starting with the HF/6-31+G(d) equilibrium structure, (b) MP2/6-31+G(d) starting with the structure in panel (a), and (c) the B3LYP/6-31+G(d) structure obtained from the structure in panel (b). The Li-O distances are quite comparable in all cases, suggesting that the B3LYP and MP2 descriptions of the coordination of THF to the Li atoms are quite comparable. On the other hand, there are significant differences between the hexagonal rings of the dimer obtained from the two treatments. We note the $\mathrm{Li}-\mathrm{Li}$, the F-F, and the C-C distances in particular. Panel (c) shows that the DFT equilibrium structure can be recovered from the MP2 structure quite accurately, eliminating the possibility that there may be local minima in the energy landscape 
corresponding to both structures. We have examined the case of $\mathrm{X}=\mathrm{Cl}$ and found similar behavior.

\section{*** Suggested location of Fig $8 * * *$}

The structural differences are reflected in the differences in the MP2 energy between the structures in panels (b) and (a) id Fig. 8, which we designate as $E_{\mathrm{MP} 2 / \mathrm{MP} 2}-E_{\mathrm{MP2} / / \mathrm{B} 3 \mathrm{LY} \text {. }}$ These differences are $-6.23 \mathrm{kcal} / \mathrm{mol}$ for $\mathrm{X}=\mathrm{F},-11.16 \mathrm{kcal} / \mathrm{mol}$ for $\mathrm{X}=\mathrm{Cl}$, and $-3.78 \mathrm{kcal} / \mathrm{mol}$ for $\mathrm{X}=$ $\mathrm{Br}$. The analogous energy differences for 7•4THF for $\mathrm{X}=\mathrm{F}, \mathrm{Cl}$ and $\mathrm{Br}$ are, respectively, -6.35 , -7.32, and $-3.25 \mathrm{kcal} / \mathrm{mol}$ respectively. The energy differences for the trisolvated species range from $-3.15 \mathrm{kcal} / \mathrm{mol}$ for $\mathbf{7} \cdot 4 \mathrm{THF}(\mathrm{X}=\mathrm{Br})$ to $-5.23 \mathrm{kcal} / \mathrm{mol}$ for $\mathbf{7} \cdot 4 \mathrm{THF}(\mathrm{X}=\mathrm{F})$, once again the MP2//B3LYP energy being always higher than the MP2//MP2 energy. At the same time, $E_{\mathrm{MP} 2 / \mathrm{MP} 2}-E_{\mathrm{MP} 2 / \mathrm{B} 3 \mathrm{LYP}}$ for THF is only $-0.17 \mathrm{kcal} / \mathrm{mol}$. It is easy to see now that these absolute energy differences quoted above account for the large differences between the $\Delta U_{0}^{\circ}$ and $\Delta G^{\circ}$ differences between MP2 and MP2//B3LYP levels of theory in Table 7. On the other hand, the difference $E_{\mathrm{MP} 2 / \mathrm{MP} 2}-E_{\mathrm{MP} 2 / \mathrm{B} 3 \mathrm{LYP}}$ for gas phase dimers $\mathbf{6}$ and $\mathbf{7}$ are very small, ranging from $0.22 \mathrm{kcal} / \mathrm{mol}$ for $\mathbf{6}(\mathrm{X}=\mathrm{F})$ to $-1.1 \mathrm{kcal} / \mathrm{mol}$ for $\mathbf{7}(\mathrm{X}=\mathrm{Cl})$. This suggests that the interaction of the Li with the THF solvent molecules has a significant influence on the structural and energetic predictions of the two levels of theory for parts of the molecule other than the Li-O bond.

The physically unreasonable prediction of the B3LYP in Table 7, that the trisolvated species is more stable, leads us to attach more importance to the MP2 results for these cases. The long range interactions that determine the structural parameters of the dimeric ring are also among the types of interactions with which the second-generation density functionals, even a highly successful hybrid functional like B3LYP, have difficulty. ${ }^{39}$ Therefore, we focus mainly on MP2 results for solvated species from this point forward, with the exception of Table 11. 
Several attempts were made to locate a TS structure for the concerted insertion reaction of the tetrasolvated dimer with ethylene, but steric constraints proved to be too hard to overcome. KZP report tetrasolvated dimeric TS structures in DME solvent, ${ }^{1}$ which points to yet another difference in the cyclopropanation reactions of $\mathrm{LiCH}_{2} \mathrm{X}$ in DME and THF. As mentioned earlier, it is possible that the more rigid structure of the THF ring and its stronger binding to the Li atom introduce steric effects not present in the case of more flexible ethereal solvent molecules.

TS structures were successfully located for the reaction of the trisolvated form, which are labeled as TS 8.3THF and TS 9·3THF for the concerted and stepwise reactions of $\mathbf{6}$, respectively, and TS $\mathbf{1 0} \cdot 3 \mathrm{THF}$ and TS $\mathbf{1 1 \cdot 3 T H F}$ respectively for the analogous reactions of $\mathbf{7}$. Table 8 summarizes the MP2 free energy changes associated with the reactions. The figures of the TS structures are provided in the Supporting Information.

\section{*** Suggested location of Table $8 * * *$}

The results tabulated in Table 8 show that, compared to the case of the gas-phase dimers (Table 4), the barriers are significantly higher for both the concerted and stepwise mechanisms. For example, the $\Delta U_{0, \mathrm{MP} 2}^{\ddagger}$ and $\Delta G_{\mathrm{MP} 2}^{\ddagger}$ for TS $8(\mathrm{X}=\mathrm{F})$ for the gas phase dimer $\mathbf{6}$ are 6.70 and $11.60 \mathrm{kcal} / \mathrm{mol}$, respectively (Table 4), compared to 19.76 and $17.85 \mathrm{kcal} / \mathrm{mol}$ respectively in THF. The barriers for the stepwise reaction also increase for this species, from 23.56 and 29.21 $\mathrm{kcal} / \mathrm{mol}$ in the gas phase $\left(\Delta U_{0}^{\ddagger}\right.$ and $\Delta G^{\ddagger}$, respectively, Table 4$)$ to 33.46 and $32.68 \mathrm{kcal} / \mathrm{mol}$ in THF. This trend appears to be absent in DME solvent. For that case, KZP report $\Delta U_{0}^{\ddagger}$ for $\mathbf{6}$ (the only dimeric form they studied) of $5.9 \mathrm{kcal} / \mathrm{mol}$ in gas phase (B3LYP/6-311G(d,p); Figure 3 of Ref. 1) and $5.8 \mathrm{kcal} / \mathrm{mol}$ for the tetrasolvated case (Figure 6 of Ref. 1). However, similar to the gas phase, the barriers for the stepwise pathway for the solvated dimeric species remain higher than that for the concerted mechanism in both THF and DME. Thus, combining our results, the 
experimentally observed preference for the concerted pathway can be confirmed by computational results in DME and THF for the dimeric species.

Another significant difference between the behavior of gas phase and THF-solvated dimers is that the formation of intermediate $3 \cdot 2 \mathrm{THF}$ according to

$$
\begin{aligned}
& \mathrm{H}_{2} \mathrm{C}=\mathrm{CH}_{2}+\left(\mathrm{Li}-\mathrm{CH}_{2}-\mathrm{X}\right)_{2} \cdot 4 \mathrm{THF} \rightarrow \mathrm{Li}-\left(\mathrm{CH}_{2}\right)_{3}-\mathrm{X} \cdot 2 \mathrm{THF}+\mathrm{Li}-\mathrm{CH}_{2}-\mathrm{X} \cdot 2 \mathrm{THF} \\
& \text { 3.2THF }
\end{aligned}
$$

is thermodynamically unfavorable at $173.15 \mathrm{~K}$, as shown in Table 9. Therefore, in additional to the higher barriers, the stepwise mechanism may be frustrated in THF by the relative instability of the required reactive intermediate. KZP did not study the carbometalation pathway for the DME-solvated dimer and, therefore, a comparison cannot be made.

\section{*** Suggested location of Table $9 * * *$}

The MP2 free energy profiles of the monomeric and dimeric $\mathrm{LiCH}_{2} \mathrm{X}$ in $\mathrm{THF}$ solvent are presented in Figure 11. For clarity, only dimer 6 is shown. As can be ascertained from Tables 79, the energy profile for dimer $\mathbf{7}$ is not qualitatively different.

\section{*** Suggested location of Fig $9 * * *$}

\section{E. Reactions of gas phase and THF solvated tetramers with ethylene}

The formation of the tetramer from the dimer is highly favored in the gas phase. Since dimers are much more stable than the monomers, we examine the formation of tetramers from the dimers, taking dimer $\mathbf{6}$ as a representative.

$$
\underset{6}{2\left(\mathrm{LiCH}_{2} \mathrm{X}\right)_{2}} \rightarrow\left(\mathrm{LiCH}_{2} \mathrm{X}\right)_{4}
$$

The relevant $\Delta U_{0}^{\circ}$ and $\Delta G^{\circ}$ data are summarized in Table 10. Note that tetramerization is even more favorable in nonpolar solvents, in which case each free energy change shown will further 
decrease by $2 \times 0.91=1.82 \mathrm{kcal} / \mathrm{mol}$ at $173.15 \mathrm{~K}$ (see the paragraph above Eq. 6). Also summarized in Table 10 are the $\Delta U_{0}^{\ddagger}$ and $\Delta G^{\ddagger}$ for the concerted and stepwise reactions, proceeding through TS 12 and TS 13, respectively:

$$
\begin{aligned}
& \mathrm{H}_{2} \mathrm{C}=\mathrm{CH}_{2}+(\mathrm{LiCHX})_{4} \rightarrow \text { TS } 12 \text { (concerted mechanism) } \\
& \mathrm{H}_{2} \mathrm{C}=\mathrm{CH}_{2}+\left(\mathrm{LiCH}_{2} \mathrm{X}\right)_{4} \rightarrow \text { TS } 13 \text { (stepwise mechanism) }
\end{aligned}
$$

The MP2 structures for the tetramer, TS 12, and TS $\mathbf{1 3}$ are given in Figure 10. Simply as a visual aid, the tetramer is visualized in these figures as two units of dimer $\mathbf{6}$. While the structure of TS 12 in the vicinity of the alkene double bond and the methylene group being inserted into it are comparable to TS $\mathbf{1}$ and TS $\mathbf{8}$, the tetrameric transition state for the stepwise insertion, TS 13, does not have a four-membered structure similar to the analogous reactions of the monomer (Figure 2, TS 2) and dimer 6 (Figure 6, TS 10).

*** Suggested location of Fig. $10 * * *$

\section{*** Suggested location of Table $10 * * *$}

The $\Delta U_{0, \mathrm{~B} 3 \mathrm{LYP}}^{\ddagger}$ for the concerted and stepwise mechanisms of 4.53 and $30.94 \mathrm{kcal} / \mathrm{mol}$, respectively, for $\mathrm{X}=\mathrm{F}$ compares well with the 4.9 and $30.8 \mathrm{kcal} / \mathrm{mol}$ reported by KZP (Figure 3(C) of Ref. 1) for the same processes. In the case of the tetramers also, a very clear preference for the concerted mechanism is observed.

We also examined the energetics of tetramerization in THF solvent, relative to the tetrasolvated dimer $\mathbf{6}$. For steric reasons, it appears unlikely that the primary solvation sphere of the tetramer will contain more than one THF coordinated to each lithium, an assumption supported by x-ray structures of other tetrameric organolithium species. ${ }^{40}$ Thus, Table 11 reports the energy changes associated with the process

$$
2\left(\mathrm{LiCH}_{2} \mathrm{X}\right)_{2} \cdot 4 \mathrm{THF} \rightarrow\left(\mathrm{LiCH}_{2} \mathrm{X}\right)_{4} \cdot 4 \mathrm{THF}+4 \mathrm{THF}
$$


In Table 11, we also include B3LYP and MP2//B3LYP results to show, for the final time, the great discrepancy between B3LYP and MP2 geometries and energies when coordinated THF molecules are involved.

\section{*** Suggested location of Table $11 * * *$}

As in the case of Table 7, Table 11 displays large discrepancies between the B3LYP and MP2, and also between MP2 and MP2//B3LYP energies, implying that the geometries found by B3LYP are significantly different from those obtained by MP2. The energy differences $E_{\text {MP2//MP2 }}$ $-E_{\mathrm{MP} 2 / \mathrm{B} 3 \mathrm{LYP}}$ for the solvated tetramers for $\mathrm{X}=\mathrm{F}, \mathrm{Cl}$, and $\mathrm{Br}$ are, respectively, $-7.11,-9.04$, and $-4.68 \mathrm{kcal} / \mathrm{mol}$. The energy differences noted earlier for the tetra-solvated dimeric species get magnified by a factor of 2 in Eq. (15). The combined differences in absolute energies are sufficient to account for the large differences between the MP2 and MP2//B3LYP results tabulated in Table 11. As one would expect from Table 10, the differences $E_{\mathrm{MP} 2 / \mathrm{MP} 2}-$ $E_{\mathrm{MP} 2 / \mathrm{B} 3 \mathrm{LYP}}$ for the gas phase tetramers are quite small, ranging from $-0.16 \mathrm{kcal} / \mathrm{mol}$ for $\mathrm{X}=\mathrm{F}$ to $-1.42 \mathrm{kcal} / \mathrm{mol}$ for $\mathrm{X}=\mathrm{Cl}$.

In striking contrast to the gas phase or nonpolar solvents (Table 10), the $\Delta U_{0}^{\circ}$ values in Table 11 shows that the formation of the tetramer is endoergic and its formation is thermodynamically unfavorable at the MP2 level of theory. This dramatic reversal of gas-phase thermodynamics appear to be primarily due to the steric effects introduced by the explicit coordination of THF ligands. This conclusion is suggested by comparing the MP2 free energies in Table 11 to the results of taking solvent effects into account through the Polarizable Continuum Model (PCM) ${ }^{41,42}$ for the dimer and tetramer, shown in Table 12 . The PCM calculations for Table 12 were done for dimer $\mathbf{6}$ and the tetramer at gas phase MP2 geometries 
using HF/6-31+G(d) and UAHF radii. Table 12 shows the gas phase $\Delta G_{\mathrm{MP} 2}^{\circ}$ for Eq. (12), adds the solvation free energy, and includes the correction for changing the standard state from $1 \mathrm{~atm}$ at $173.15 \mathrm{~K}(1 \mathrm{~mol} / 14.21 \mathrm{~L})$ to $1 \mathrm{~mol} / \mathrm{L}$ that was mentioned in Section 2 . In spite of the slight destabilization of the tetramer relative to the dimer due to solvation, this treatment still predicts that tetramerization is a thermodynamically favorable process in a solvent with $\varepsilon=7.85$. Therefore, the positive $\Delta G_{\mathrm{MP2}}^{\circ}$ for tetramerization in Table 11 must be the result of further destabilization of the tetramer due to steric effects which, of course, are not described by continuum solvation models.

Since MP2 results indicate that the dominant species of $\mathrm{LiCH}_{2} \mathrm{X}$ in THF solution is likely to be the dimer, and also because of the computational difficulties associated with treating such large systems at MP2 level of theory (72 atoms for the tetrasolvated tetramer), we did not examine the barrier heights for the reactions of the tetrasolvated tetramer with ethylene.

\section{*** Suggested location for Table $12 * * *$}

\section{F. Reactions of gas phase dimers with dimethylbutene}

In this Section, we report on the reactions of $\left(\mathrm{LiCH}_{2} \mathrm{X}\right)_{2}$ with 2,3-dimethyl-2-butene, $\left(\mathrm{CH}_{3}\right)_{2} \mathrm{C}=\mathrm{C}\left(\mathrm{CH}_{3}\right)_{2}$, abbreviated as $\mathrm{DMB}$ for convenience. These studies were undertaken to examine whether the conclusions drawn from the preceding sections and the studies of KZP were applicable only to ethylene.

The transition state structures for the direct and stepwise pathways are given in Figure 11 for the representative case of $\mathrm{X}=\mathrm{Br}$, and are oriented so that comparisons can be made with the structures of transition states $\mathbf{8}$ and $\mathbf{9}$ for ethylene in Figures 6 and 7. The concerted mechanism involving dimer $\mathbf{6}$ passes through TS $\mathbf{1 4}$ while dimer $\mathbf{7}$ undergoing the same reaction passes through TS 15. Many structural aspects of the transition states $\mathbf{1 4}$ and $\mathbf{1 5}$ are comparable to 
analogous structures involving ethylene, namely, TS 8 (Figure 6) and 9 (Figure 7). The stepwise reactions of dimers 6 and 7 with DMB pass through transition states 16 and 17, respectively, which are structurally similar to TS $\mathbf{1 0}$ (Figure 6) and TS $\mathbf{1 1}$ (Figure 7). As in the case of ethylene, we were able to identify relatively stable pre-reactive complexes in which one of the $\mathrm{Li}$ atoms of the dimer interacted strongly with the alkene double bond. In keeping with the numbering conventions adopted earlier, these are designated as $\mathbf{1 6}^{\prime}$ and $\mathbf{1 7}^{\prime}$, respectively for dimers 6 (leading to TS 16) and 7 (leading to TS 17), and are shown in Figure 13. Structurally, these are similar to the structures for $\mathbf{1 0}^{\prime}$ (Figure 6) and $\mathbf{1 1}^{\prime}$ (Figure 7).

\section{*** Suggested location for Fig. 11 ***}

The zero-point inclusive relative (with respect to reactants) energies at $0 \mathrm{~K}, \Delta U_{0}^{\circ}$, and relative free-energies at $173.15 \mathrm{~K}$ and standard pressure, $\Delta G^{\circ}$, for the processes studied are summarized in Table 13. The analogous results for ethylene are given in Table 4. It is clear from Table 13 that the concerted mechanism is clearly preferred over the stepwise pathway at all levels of theory examined. The barriers for the concerted pathway are generally lower than those for ethylene (compare to TS 8 and TS 9 in Table 4), especially in the case of dimer 7, while those for the stepwise pathway are higher, indicating an even stronger preference for the direct pathway compared to that of ethylene.

*** Suggested location for Table $13 * * *$

A couple of "anomalies" to be noted in Table 13 are the negative values for $\Delta U_{0}^{\circ}$ at the MP2 and MP2//B3LYP levels of theory for TS $\mathbf{1 5}$ for the case of $\mathrm{X}=\mathrm{Br}$. To investigate these further, we performed MP2 level IRC calculations for both dimers. These calculations reveal that as the carbenoid dimer approaches the alkene to form transition states $\mathbf{1 4}$ or $\mathbf{1 5}$ (dimer $\mathbf{6}$ or $\mathbf{7}$, respectively) one of the lithium atoms starts to interact with one of the $s p^{3}$ carbons of the DMB. 
These interactions are long-range and appear to be electrostatic in nature. Figure 12 shows the MP2/6-31+G $(d)$ structures of transition states $\mathbf{1 4}$ and $\mathbf{1 5}$ from perspectives that make it easier to visualize these interactions, along with charges fitted to the electrostatic potential using the Merz-Singh-Kollman algorithm. ${ }^{43}$

\section{*** Suggested location for Fig. 12}

In the case of bromo dimer 7 , the IRC shows clear indications that the interaction gives rise to a weak pre-reactive complex, since its energy becomes even more negative relative to the reactants for negative values of the reaction coordinate. As shown in Figure 13, a "physically reasonable” interpolation from the last calculated point on the IRC to the asymptotic reactants at $E=0 \mathrm{kcal} / \mathrm{mol}$ suggest that the minimum energy of the IRC may be around $-3.8 \mathrm{kcal} / \mathrm{mol}$ at a value of the reaction coordinate of approximately -2.4 . The formation of this complex is sufficient to lower the zero-point energy inclusive reaction barriers $\Delta U_{0}^{\ddagger}$ for TS $\mathbf{1 5}$ to the small negative values reported in Table 13.

\section{*** Suggested location for Fig. 13}

The interactions responsible for this pre-complex formation appear to be much weaker in the case of dimer 6. A simplistic electrostatic potential calculation can be done to estimate the strength of the interactions using the ESP fitted charges and Li-C distances shown in Fig. 12 $\left(\sim q_{1} q_{2} / r\right)$. This shows that the electrostatic potential in the case of TS 14 for $\mathrm{X}=\mathrm{Br}$ (dimer $\left.\mathbf{6}\right)$ is only $62 \%$ as strong as that in TS $\mathbf{1 5}$ (dimer 7). The IRC leading to the reactants from TS $\mathbf{1 4}$ for $\mathrm{X}=\mathrm{Br}$, interpolated as described earlier and shown in Fig. 13, suggests the presence of a shallow minimum of about $-0.50 \mathrm{kcal} / \mathrm{mol}$ relative to the reactants at a value of the reaction coordinate of approximately -3.0. The simplistic electrostatic potential calculation mentioned above also shows that similar interactions between Li and the $s p^{3}$ carbons of the alkene in the case of dimer 
7 for $\mathrm{X}=\mathrm{Cl}$ is about $71 \%$ as strong as that in TS $\mathbf{1 5}$ (dimer 7) for $\mathrm{X}=\mathrm{Br}$. The MP2/6-31+G(d) IRC for the chloro dimer 7 (TS 15) offers strong hints that it may fall to small negative energies with respect to asymptotic reactants, but convergence difficulties for large enough negative values of the reaction coordinate prevented us from confirming this. When interpolated as before, the IRC shows a minimum of about $-0.60 \mathrm{kcal} / \mathrm{mol}$ at a value of the reaction coordinate of approximately -4.0, as shown in Fig. 13.

The MP2/6-31+G(d) IRC calculation for both fluoro dimers could not be extended far from the transition states towards the reactants because of convergence difficulties. However, the overall shape of the IRC that could be mapped out provided no hints of pre-reactive complex formation in either case. Whether or not the relative energy along the IRC falls below zero for negative values of the reaction coordinate (the "reactant" side of the barrier), the relatively stronger long-range interactions in the case of dimers 7 may be responsible for lowering the reaction barriers for forming TS $\mathbf{1 5}$ for all three halogens compared to those for the formation of TS 14 from dimer 6. It is possible that similar interactions may cause the barriers for the concerted mechanism to remain low for longer chain alkenes, thus favoring the concerted mechanism in general for the insertion of a methylene group into a carbon-carbon double bond.

Although hydrogens are not shown in the structures in Fig. 12 for the sake of clarity, we also considered the interactions between the hydrogens bonded to the $s p^{3}$ carbon which interacts with the lithium in Fig. 14. The Merz-Singh-Kollman algorithm assigns partial positive charges ( +0.10 to +0.16 depending on the dimer and the halogen) to these hydrogens and none of them are directed towards the $\mathrm{Li}$ atom. However, metal-hydrogen interactions are common in organolithium chemistry and they may also play a role in determining the relative strengths of the long-range interactions discussed above. 
Even though B3LYP transition state structures are qualitatively similar to those predicted by MP2, the IRC's calculated using B3LYP/6-31+G(d) show no indication that pre-reactive complexes are being formed in the case of either dimer for any halogen. The electrostatic interactions are strongest in the case of TS $\mathbf{1 5}$ for $\mathrm{X}=\mathrm{Br}$ in the case of DFT also, but the IRC in this case is such that the distance between the $\mathrm{Li}$ of the dimer and the $s p^{3}$ carbons of DMB increases rapidly as the reaction coordinate assumes negative values. This may be a reflection of the relative inability of B3LYP to account for long-range non-bonded interactions, ${ }^{39}$ on which we commented earlier, in connection with THF-solvated structures.

Given these gas phase results for DMB and their qualitative similarity in essential aspects to the gas phase results for ethylene (concerted reaction significantly favored over the stepwise mechanism), we expect the mechanisms of DMB reacting with the carbenoid dimers in THF solution to also be qualitatively similar to those observed in the case of ethylene.

\section{Summary and Conclusions}

This paper describes a detailed computational study of the cyclopropanation reactions of halomethyllithiums. Two mechanisms have been proposed for these reactions, namely the direct insertion of $\mathrm{CH}_{2}$ into the alkene double bond, ${ }^{2,3,5}$ (methylene transfer) and a stepwise mechanism involving carbolithiation. ${ }^{4}$ Although experimental evidence for the concerted mechanism is strong, it has been difficult to completely rule out the stepwise pathway. Until recently, computational chemistry was also not very helpful because calculations were limited to monomeric species in the gas phase, which have yielded comparable reaction barriers for both processes. ${ }^{6,7}$ One novelty of the work of KZP ${ }^{1}$ and the present report is the consideration of the reactions of the halomethyllithium dimers and tetramers which are significantly more stable than the monomers and thus expected to be the dominant reagent species. The calculated reaction 
barriers for the reactions of dimers show a clear preference for the concerted pathway in the gas phase, non-polar solvents, and in two polar solvents - DME (Ref. 1), and THF (present work). In the case of tetramers, there is a clear preference for the concerted reaction in the gas phase and in non-polar solvents. The computational challenges of dealing with a fully solvated tetramer prevented us from calculating barrier heights for the reaction in THF but, based on the comparison of the barrier heights for the gas phase and THF-solvated dimers, it is reasonable to expect that the barrier heights for the solvated tetramer for the concerted reaction will be comparable to, or lower than that for the gas phase tetramer, and that the barrier height for the stepwise pathway will be comparable or higher than that for the gas-phase tetramer. Thus consideration of the aggregated species in computational modeling establishes a clear preference for direct methylene transfer mechanism for the cyclopropanation reactions of halomethyllithiums. The work of KZP and the present report thus resolve a question that has been open since the proposal of the two-step pathway by Hoberg in 1962 and its refutation by Burger and Huisgen in 1970, both on the basis of experimental evidence.

Our work shows that ethylene dimer 7, which was not investigated by KZP, provides a slightly lower energy pathway for the concerted gas phase reaction (Table 4). In the reactions of DMB with the dimeric carbenoids in the gas phase, reported here for the first time, the reaction barriers for the concerted gas phase reactions of dimer $\mathbf{7}$ are significantly lower than those for dimer 6 (Table 13), thanks to long-range interactions between the approaching lithium carbenoid and the $s p^{3}$ carbons of the butene. These interactions and their tendency to lower the reaction barriers for the concerted reaction offer strong indication that the preference for the concerted pathway observed in the case of ethylene and dimethylbutene may be generalized to other alkenes. 
The greater polarity of THF $(\varepsilon=7.85)$ compared to DME $(\varepsilon=4.34)$ and the rigidity of the ring-structure gives rise to interesting differences in steric and energetic effects. The carbolithiation pathway of bis-THF solvated monomers and dimers do not appear to pass through pre-reactive complexes while Ref. 1 indicates that such complexes are formed in DME. The tetrasolvated dimers in THF appear to have difficulty forming tetrasolvated transition states (trisolvated transition states were easily identified) because of the strongly coordinated THF ligands while KZP report tetrasolvated transition states in DME. In connection to Table 8, we observed that, compared to the gas phase reactions, THF solvation increased the barrier heights for both the concerted and carbolithiation pathways for dimers 6 and 7. In contrast, at least for dimer $\mathbf{6}$ and the $\mathrm{X}=\mathrm{F}$ case, KZP report that reaction barriers in DME are comparable to those in the gas phase.

Since the halogens are not directly involved in the reaction, the significant differences in electronegativity and ionic radii of the three halogens play only an indirect role in determining the energetic of the reaction. Reaction barriers for $\mathrm{X}=\mathrm{F}$ and $\mathrm{Br}$ are found to be generally lower than those for $\mathrm{X}=\mathrm{Cl}$ but for different reasons. In the case of $\mathrm{X}=\mathrm{F}$, the great affinity of $\mathrm{Li}$ for $\mathrm{F}$ is responsible for the formation of transition states which are stabilized by the interaction of $\mathrm{Li}$ and $\mathrm{F}$ while the lower barriers in the case of $\mathrm{X}=\mathrm{Br}$ are related to the relatively weaker bonding of $\mathrm{Br}$ to the methyl carbon and $\mathrm{Li}$. The affinity of the $\mathrm{Li}$ and $\mathrm{F}$ towards each other is reflected in the $\Delta G^{\circ}$ for the formation of the $\mathrm{Li}-\mathrm{CH}_{3}-\mathrm{X}$ - LiX mixed aggregates. At the B3LYP and MP2 levels, the $\Delta G^{\circ}$ for the formation of the fluoro mixed aggregates is more negative by about 10 $\mathrm{kcal} / \mathrm{mol}$ than for the bromo, with the chloro falling in between. In the concerted reactions of DMB, long-range interactions between the carbenoid dimer 7 and the $s p^{3}$ carbons of the alkene lead to the formation of weak pre-reactive complexes in the case of the relatively easily 
polarizable $\mathrm{Br}$. The strong interaction of $\mathrm{F}$ with $\mathrm{Li}$ and its significantly lower polarizability appear to weaken such long-range interactions with carbon in the case of $X=F$. Once again, the $\mathrm{X}=\mathrm{Cl}$ case falls in between, as discussed in the previous section.

Structure optimization using B3LYP followed by single-point MP2 calculation (MP2//B3LYP) appears to be a highly economical and reliable procedure in the case of gas phase molecules and an acceptable compromise in the case of solvated monomers. In these cases, the energy differences calculated from MP2-optimized structures are quite close to the MP2//B3LYP results. However, the non-covalent and weak interactions responsible for dimerization and the dipole interactions in the solvated species appear to cause problems for B3LYP. The analysis presented in Fig. 8 and the related discussion reveals that the B3LYP and MP2 descriptions of the coordination of THF to the Li atoms are quite similar. However, the presence of the solvent molecules leads the two methods to predict equilibrium structures with large structural differences (see Tables 7 and 11) for parts of the molecule other than the Li-O bond. In these cases, contradictory predictions of relative stabilities for solvated dimers by B3LYP and MP2 suggest that the MP2 predictions are more reliable.

The comparison of PCM vs. explicit solvation by THF ligands (Tables 11 and 12) offer support to the statement made in the Introduction that explicit inclusion of solvent molecules is often necessary in organolithium chemistry to describe the steric effects in the primary solvation sphere. In this context, the apparent failure of B3LYP at predicting THF-coordinated structures comparable to those obtained with MP2, at considerably greater computational cost, is rather disheartening. We are currently exploring the performance of the most recent generation of DFT functionals ${ }^{39}$ for these systems. 


\section{Acknowledgments}

This work was supported in part by NSF grant INT-0454045, CHE-0643629, and DMR0414903. This research used resources of the National Energy Research Scientific Computing Center, which is supported by the Office of Science of the U.S. Department of Energy under Contract No. DE-AC03-76SF00098. The use of the IBM p5-575 computers provided by the Louisiana Optical Network Initiative (LONI) is gratefully acknowledged.

Supporting Information Available: Optimized MP2 structures, energies of all reactants, products, and TS structures are provided in PDF format. Calculations of $\Delta E, \Delta U_{0}^{\circ}$ and $\Delta G^{\circ}$ at the HF, B3LYP, MP2, MP2//B3LYP levels for the results reported in this paper are provided in the form of an Excel file. This material is available free of charge on the web at http://www.csj.jp/journals/bcsj/. 


\section{References}

1 Z. Ke, C. Zhao, D. L. Phillips, J. Org. Chem. 2007, 72, 848.

2 H.E. Simmons, R.D. Smith, J. Am. Chem. Soc. 1958, 80, 5323.

3 H.E. Simmons, R.D. Smith, J. Am. Chem. Soc. 1959, 81, 4256.

4 H. Hoberg, Leibigs Ann. Chem. 1962, 656, 1.

$5 \quad$ U. Burger, R. Huisgen, Tetrahedron Lett. 1970, 3049.

6 H. C. Stiasny, R. W. Hoffmann, Chem. Eur. J. 1995, 1, 619.

7 M. Nakamura, A. Hirai, E. Nakamura, J. Am. Chem. Soc. 2003, 125, 2341.

8 H. Hermann, J. C. Lohrenz, A. Kuhn, G. Boche Tetrahedron, 2000, 56, 4109.

9 C. Y. Zhao, D. Q. Wang, D. L. Phillips, J. Am. Chem. Soc. 2002, 124, 12903.

10 D. Q. Wang, D.L. Phillips, W. H. Fang, Organometallics, 2002, 21, 5901.

11 C. Y. Zhao, D. Q. Wang, D. L. Phillips, J. Am. Chem. Soc. 2003, 125, 15200.

12 D. Q. Wang, C. Y. Zhao, D. L. Phillips, J. Org. Chem. 2004, 69, 5512.

13 Z. Ke, Y. Zhou, H. Gao, C. Y. Zhao, D. L. Phillips, Chem. Eur. J. 2007, 13, 6724.

14 L. M. Pratt, N. V. Nguyen, O. Kwon Chem. Lett. 2009, 38, 574.

15 V. Capriati, L. Degennaro, R. Favia, S. Florio, R. Luisi, Org. Lett. 2002, 4, 1551.

16 D. M. Hodgson, N. J. Reynolds, S. J. Coote, Org. Lett. 2004, 6, 4187.

17 S. H. Wiedemann, A. Ramirez, D. B. Collum, J. Am. Chem. Soc. 2003, 125, 15893.

18 T. Satoh, Chem. Rev. 1996, 96, 3303.

19 P. J. Campos, D. Sampedro, M. A. Rodriguez, Organometallics 1998, 17, 5390.

20 L. M. Pratt, B. Ramachandran, J. D. Xidos, C. J. Cramer, D. G. Truhlar, J. Org. Chem. 2002, 67, 7607.

21 L. M. Pratt, I. M. Khan, J. Comp. Chem. 1995, 16, 1067. 
22 F. E. Romesberg, D. B. Collum, J. Am. Chem. Soc. 1992, 114, 2112.

J. L. Rutherford, D. B. Collum, J. Am. Chem. Soc. 2001, 123, 199.

24 C. Gonzalez, H. B. Schlegel, J. Chem. Phys. 1989, 90, 2154.

C. Gonzalez, H. B. Schlegel, J. Phys. Chem. 1990, 94, 5523.

L. M. Pratt, S. Merry, S. C. Nguyen, P. Quan, B. T. Thanh, Tetrahedron, 2006, 62, 10821.

M. J. Frisch, G. W. Trucks, H. B. Schlegel, G. E. Scuseria, M. A. Robb, J. R. Cheeseman, J. A. Montgomery Jr., T. Vreven, K. N. Kudin, J. C. Burant, J. M. Millam, S. S. Iyengar, J. Tomasi, V. Barone. B. Mennucci, M. Cossi, G. Scalmani, N. Rega, G. A. Petersson, H. Nakatsuji, M. Hada, M. Ehara, K. Toyota, R. Fukuda, J. Hasegawa, M. Ishida, T. Nakajima, Y. Honda, O. Kitao, H. Nakai, M. Klene, X. Li, J. E. Knox, H. P. Hratchian, J. B. Cross, C. Adamo, J. Jaramillo, R. Gomperts, R. E. Stratmann, O. Yazyev, A. J. Austin, R. Cammi, C. Pomelli, J. W. Ochterski, P. Y. Ayala, K. Morokuma, G. A. Voth, P. Salvador, J. J. Dannenberg, V. G. Zakrzewski, S. Dapprich, A. D. Daniels, M. C. Strain, O. Farkas, D. K. Malick, A. D. Rabuck, K. Raghavachari, J. B. Foresman, J. V. Ortiz, Q. Cui, A. G. Baboul, S. Clifford, J. Cioslowski, B. B. Stefanov, G. Liu, A. Liashenko, P. Piskortz, I. Komaromi, R. L. Martin, D. J. Fox, T. Keith, M. A. Al-Laham, C. Y. Peng, A. Nanayakkara, M. Challacombe, P. M. W. Gill, B. Johnson, W. Chen, M. W. Wong, C. Gonzalez, J. A. Pople, GAUSSIAN 03 Gaussian, Inc., Pittsburgh. PA, 2003. C. Gonzalez and H. B. Schlegel, J. Chem. Phys. 1989, 90, 2154; J. Phys. Chem. 1990, 94, 5523.

J. D. Thompson, C. J. Cramer, D. G. Truhlar, J. Chem. Phys. 2003, 119, 1661.

30 L. M. Pratt, V. N. Nguyen, B. Ramachandran, J. Org. Chem., 2005, 70, 4279. 
31 U. P. Govender, T. M. Letcher, S. K. Garg, J. C. Ahluwalia, J. Chem. Eng. Data 1996, 41, 147.

32 L. M. Pratt, A. Streitwieser, J. Org. Chem., 2003, 68, 2830.

33 L. M. Pratt, S. Mogali, K. Glinton, J. Org. Chem., 2003, 68, 6484.

34 L. M. Pratt, R. Mu, J. Org. Chem., 2004, 69, 7519.

35 L. M. Pratt, Bull. Chem. Soc. Japan, 2005, 78, 890.

36 L. M. Pratt, N. V. Nguyen, L. T. Le, J. Org. Chem., 2005, 70, 2294.

37 L. M. Pratt, N. V. Nguyen, J. Phys. Chem. A 2006, 110, 687.

38 L. M. Pratt, D. H. Phan-Tran, P. T. T Tran, N. V. Nguyen, Bull. Chem. Soc. Japan, 2007, 80, 1587.

39 Y. Zhao, D. G. Truhlar, J. Chem. Theory and Comput. 2007, 3, 289.

40 R. Amstutz, W. B. Schweizer, D. Seebach, J. D. Dunitz, Helv. Chim. Acta 1981, 64, 2617.

41 M. T. Cancès, B. Mennucci, and J. Tomasi, J. Chem. Phys. 1997, 107, 3032; M. Cossi, V. Barone, B. Mennucci, and J. Tomasi, Chem. Phys. Lett. 1998, 286, 253; B. Mennucci and J.Tomasi, J. Chem. Phys. 1997, 106, 5151.

42 M. Cossi, G. Scalmani, N. Rega, and V. Barone, J. Chem. Phys. 2002, 117, 43.

43 U. C. Singh and P. A. Kollman, J. Comp. Chem. 1984, 5, 129; B. H. Besler, K. M. Merz Jr., and P. A. Kollman, J. Comp. Chem. 1990, 11, 431. 
Table 1. The zero-point inclusive energy differences at $0 \mathrm{~K}, \Delta U_{0}^{\circ}$ and free-energy differences $\Delta G^{\circ}$ at $173.15 \mathrm{~K}$ with respect to the reactants for the processes summarized in Eqs. (1) and (2) (in kcal/mol).

\begin{tabular}{|c|c|c|c|c|c|c|c|}
\hline & $\Delta U_{0}^{\circ}, \mathrm{B} 3 \mathrm{LYP}$ & $\Delta U_{0}^{\circ}, \mathrm{MP2}$ & $\begin{array}{c}\Delta U_{0}^{\circ}, \mathrm{MP2} \\
\text { //B3LYP } \\
\end{array}$ & $\begin{array}{c}\Delta U_{0}^{\circ}, \operatorname{ccsD}(\mathrm{T}) \\
\text { IIMP2 }\end{array}$ & $\Delta G_{\text {B3LYP }}^{\circ}$ & $\Delta G^{\circ}{ }_{\mathrm{MP2}}$ & $\begin{array}{c}\Delta G^{\circ}{ }_{\text {MP2II }} \\
\text { B3LYP }\end{array}$ \\
\hline \multicolumn{8}{|c|}{$\mathrm{H}_{2} \mathrm{C}=\mathrm{CH}_{2}+\mathrm{LiCH}_{3} \mathrm{X} \rightarrow \mathrm{TS} 1$} \\
\hline$X=F$ & 6.47 & 7.83 & 7.87 & 7.73 & 11.44 & 12.80 & 12.84 \\
\hline $\mathrm{X}=\mathrm{Cl}$ & 5.56 & 8.50 & 8.04 & 7.09 & 10.49 & 13.42 & 12.96 \\
\hline $\mathrm{X}=\mathrm{Br}$ & 5.42 & 6.60 & 6.49 & 5.90 & 10.49 & 11.67 & 11.56 \\
\hline \multicolumn{8}{|c|}{$\mathrm{H}_{2} \mathrm{C}=\mathrm{CH}_{2}+\mathrm{LiCH}_{3} \mathrm{X} \rightarrow \mathbf{2}^{\prime}$} \\
\hline$X=F$ & -8.60 & -10.18 & -10.24 & -10.14 & -4.46 & -6.04 & -6.10 \\
\hline $\mathrm{X}=\mathrm{Cl}$ & -8.88 & -11.03 & -11.11 & -10.89 & -4.66 & -6.81 & -6.89 \\
\hline $\mathrm{X}=\mathrm{Br}$ & -9.49 & -11.63 & -11.71 & -11.54 & -4.92 & -7.05 & -7.14 \\
\hline \multicolumn{8}{|c|}{$\mathrm{H}_{2} \mathrm{C}=\mathrm{CH}_{2}+\mathrm{LiCH}_{3} \mathrm{X} \rightarrow \mathrm{TS} 2$} \\
\hline$X=F$ & 4.11 & 7.06 & 6.93 & 8.87 & 9.38 & 12.34 & 12.20 \\
\hline $\mathrm{X}=\mathrm{Cl}$ & 6.56 & 6.39 & 6.08 & 9.07 & 12.14 & 11.97 & 11.66 \\
\hline $\mathrm{X}=\mathrm{Br}$ & 6.16 & 6.58 & 6.47 & 9.53 & 11.72 & 12.14 & 12.03 \\
\hline \multicolumn{8}{|c|}{$\mathrm{H}_{2} \mathrm{C}=\mathrm{CH}_{2}+\mathrm{LiCH}_{3} \mathrm{X} \rightarrow \mathbf{3}$} \\
\hline$X=F$ & -23.07 & -27.43 & -27.43 & -24.29 & -17.40 & -21.76 & -21.76 \\
\hline $\mathrm{X}=\mathrm{Cl}$ & -15.41 & -22.18 & -22.22 & -18.71 & -9.65 & -16.41 & -16.45 \\
\hline $\mathrm{X}=\mathrm{Br}$ & -15.08 & -20.52 & -20.47 & -16.92 & -9.28 & -14.72 & -14.66 \\
\hline \multicolumn{8}{|c|}{$\mathrm{H}_{2} \mathrm{C}=\mathrm{CH}_{2}+\mathrm{LiCH}_{3} \mathrm{X} \rightarrow$ Cyclopropane $+\mathrm{LiX}$} \\
\hline$X=F$ & -53.39 & -63.74 & -63.77 & -56.94 & -53.14 & -63.49 & -63.52 \\
\hline $\mathrm{X}=\mathrm{Cl}$ & -51.17 & -59.86 & -60.56 & -54.59 & -50.95 & -59.63 & -60.33 \\
\hline $\mathrm{X}=\mathrm{Br}$ & -48.32 & -58.63 & -58.94 & -53.15 & -48.13 & -58.43 & -58.75 \\
\hline
\end{tabular}


Table 2. The zero-point inclusive energy differences at $0 \mathrm{~K}, \Delta U_{0}^{\ddagger}$, and free-energy differences $\Delta G^{\ddagger}$ at $173.15 \mathrm{~K}$ with respect to the reactants $\mathrm{H}_{2} \mathrm{C}=\mathrm{CH}_{2}+\mathrm{LiCH}_{3} \mathrm{X}$ for the formation of TS4 and TS5, as outlined in Eq. (3) (in $\mathrm{kcal} / \mathrm{mol}$ ).

\begin{tabular}{|c|c|c|c|c|c|c|c|}
\hline & $\Delta U_{0}^{\ddagger}$, BзLYP & $\Delta U_{0}^{\ddagger}, \mathrm{MP2}$ & $\begin{array}{c}\Delta U_{0}^{\ddagger}, \text { MP2II } \\
\text { BзLYP } \\
\end{array}$ & $\begin{array}{c}\Delta U_{0}^{\ddagger}, \operatorname{ccsD}(\mathrm{T}) ! l \\
\mathrm{MP} 2\end{array}$ & $\Delta G^{\ddagger}$,B3LYP & $\Delta G^{\ddagger}, \mathrm{MP2}$ & $\begin{array}{c}\Delta G^{\ddagger}, \text { MP2II } \\
\text { BзLYP } \\
\end{array}$ \\
\hline \multicolumn{8}{|c|}{ TS 4 (anti), relative to $\mathrm{H}_{2} \mathrm{C}=\mathrm{CH}_{2}+\mathrm{LiCH}_{3} \mathrm{X}$} \\
\hline$X=F$ & 19.45 & 14.52 & 14.29 & 20.32 & 24.85 & 19.92 & 19.69 \\
\hline $\mathrm{X}=\mathrm{Cl}$ & 10.46 & 9.96 & 9.62 & 13.76 & 15.88 & 15.38 & 15.04 \\
\hline $\mathrm{X}=\mathrm{Br}$ & 9.91 & 5.61 & 5.29 & 10.29 & 15.43 & 11.14 & 10.82 \\
\hline \multicolumn{8}{|c|}{ TS 5 (syn), relative to $\mathrm{H}_{2} \mathrm{C}=\mathrm{CH}_{2}+\mathrm{LiCH}_{3} \mathrm{X}$} \\
\hline$X=F$ & 0.37 & 2.94 & 3.38 & 4.18 & 5.52 & 8.09 & 8.54 \\
\hline $\mathrm{X}=\mathrm{Cl}$ & 4.82 & 9.55 & 9.29 & 8.72 & 10.16 & 14.89 & 14.63 \\
\hline $\mathrm{X}=\mathrm{Br}$ & 5.15 & 8.61 & 8.83 & 8.06 & 10.65 & 14.11 & 14.33 \\
\hline
\end{tabular}


Table 3. The $\Delta U_{0}^{\circ}$ and $\Delta G^{\circ}$ at $173.15 \mathrm{~K}$ for the dimerization of $\mathrm{LiCH}_{3} \mathrm{X}$ in the gas phase (in $\mathrm{kcal} / \mathrm{mol}$ ).

\begin{tabular}{|c|c|c|c|c|c|c|c|}
\hline & & & $\Delta U_{0}^{\circ}, \mathrm{MP2}$ & $U_{0}^{\circ}, \operatorname{ccsD}(T$ & & & $\Delta G^{\circ}, \mathrm{MP} 2 \|$ \\
\hline & $\Delta U_{0}^{\circ}, \mathrm{B} 3 \mathrm{LYP}$ & $\Delta U_{0}^{\circ}$,MP2 & B3LYP & MP2 & $\Delta G^{\circ}$, B3LYP & $\Delta G^{\circ},{ }_{\mathrm{MP} 2}$ & B3LYP \\
\hline & & & $2 \mathrm{LiCl}$ & $\rightarrow 6$ & & & \\
\hline$X=F$ & -44.49 & -46.08 & -46.12 & -46.56 & -38.65 & -40.25 & -40.29 \\
\hline $\mathrm{X}=\mathrm{Cl}$ & -37.55 & -43.30 & -43.87 & -43.19 & -31.69 & -37.44 & -38.01 \\
\hline $\mathrm{X}=\mathrm{Br}$ & -38.08 & -42.09 & -42.41 & -41.99 & -32.17 & -36.17 & -36.50 \\
\hline & & & $2 \mathrm{LiCl}$ & $\rightarrow 7$ & & & \\
\hline$X=F$ & -43.82 & -45.09 & -45.07 & -45.50 & -38.21 & -39.48 & -39.46 \\
\hline $\mathrm{X}=\mathrm{Cl}$ & -35.64 & -41.62 & -41.95 & -41.35 & -29.53 & -35.51 & -35.84 \\
\hline$X=B r$ & -37.79 & -41.98 & -42.29 & -41.76 & -31.43 & -35.61 & -35.93 \\
\hline
\end{tabular}


Table 4. The $\Delta U_{0}^{\circ}$ and $\Delta G^{\circ}$ at $173.15 \mathrm{~K}$ for the reactions of the gas phase dimers 6 and 7 (in $\mathrm{kcal} / \mathrm{mol}$ ).

\begin{tabular}{|c|c|c|c|c|c|c|c|}
\hline & $\Delta U_{0}^{\circ}, \mathrm{B} 3 \mathrm{LYP}$ & $\Delta U_{0}^{\circ}, \mathrm{MP2}$ & $\begin{array}{c}\Delta U_{0}^{\circ} \text {,MP2II } \\
\text { B3LYP } \\
\end{array}$ & $\begin{array}{c}\Delta U_{0}^{\circ}, \operatorname{ccsD}(\mathrm{T}) \| \\
\mathrm{MP2}\end{array}$ & $\Delta G^{\circ}$, B3LYP & $\Delta G^{\circ},{ }_{\mathrm{MP} 2}$ & $\begin{array}{c}\Delta G^{\circ}, \text { MP2II } \\
\text { B3LYP } \\
\end{array}$ \\
\hline \multicolumn{8}{|c|}{$\mathrm{H}_{2} \mathrm{C}=\mathrm{CH}_{2}+\mathbf{6} \rightarrow \mathrm{TS} 8$} \\
\hline$X=F$ & 6.53 & 6.70 & 6.59 & 5.67 & 11.44 & 11.60 & 11.49 \\
\hline $\mathrm{X}=\mathrm{Cl}$ & 8.87 & 10.01 & 11.69 & 8.35 & 13.69 & 14.83 & 16.51 \\
\hline $\mathrm{X}=\mathrm{Br}$ & 5.87 & 7.28 & 7.32 & 5.74 & 11.18 & 12.59 & 12.62 \\
\hline \multicolumn{8}{|c|}{$\mathrm{H}_{2} \mathrm{C}=\mathrm{CH}_{2}+\mathbf{6} \rightarrow 10^{\prime}$} \\
\hline$X=F$ & -5.16 & -7.89 & -7.82 & -7.71 & -0.76 & -3.50 & -3.43 \\
\hline $\mathrm{X}=\mathrm{Cl}$ & -4.77 & -8.34 & -8.19 & -8.03 & -0.37 & -3.94 & -3.79 \\
\hline $\mathrm{X}=\mathrm{Br}$ & -2.96 & -5.82 & -4.97 & -5.78 & 2.06 & -0.80 & 0.06 \\
\hline \multicolumn{8}{|c|}{$\mathrm{H}_{2} \mathrm{C}=\mathrm{CH}_{2}+\mathbf{6} \rightarrow \mathrm{TS} 10$} \\
\hline$X=F$ & 21.77 & 23.56 & 23.56 & 25.10 & 27.42 & 29.21 & 29.21 \\
\hline $\mathrm{X}=\mathrm{Cl}$ & 23.32 & 24.62 & 27.79 & 27.08 & 29.24 & 30.54 & 33.71 \\
\hline $\mathrm{X}=\mathrm{Br}$ & 17.74 & 17.43 & 18.03 & 19.99 & 24.04 & 23.73 & 24.32 \\
\hline \multicolumn{8}{|c|}{$\mathrm{H}_{2} \mathrm{C}=\mathrm{CH}_{2}+\mathbf{7} \rightarrow \mathrm{TS} 9$} \\
\hline$X=F$ & 5.30 & 5.14 & 5.00 & 4.19 & 10.59 & 10.43 & 10.29 \\
\hline $\mathrm{X}=\mathrm{Cl}$ & 5.06 & 7.50 & 7.00 & 5.53 & 9.80 & 12.23 & 11.74 \\
\hline $\mathrm{X}=\mathrm{Br}$ & 8.74 & 5.36 & 5.28 & 4.04 & 13.93 & 10.55 & 10.47 \\
\hline \multicolumn{8}{|c|}{$\mathrm{H}_{2} \mathrm{C}=\mathrm{CH}_{2}+7 \rightarrow \mathbf{1 1}^{\prime}$} \\
\hline$X=F$ & -6.15 & -8.49 & -8.56 & -8.40 & -1.33 & -3.67 & -3.74 \\
\hline $\mathrm{X}=\mathrm{Cl}$ & -6.46 & -9.45 & -9.49 & -9.21 & -1.92 & -4.90 & -4.94 \\
\hline $\mathrm{X}=\mathrm{Br}$ & -7.56 & -10.68 & -10.72 & -18.89 & -2.99 & -6.10 & -6.14 \\
\hline \multicolumn{8}{|c|}{$\mathrm{H}_{2} \mathrm{C}=\mathrm{CH}_{2}+7 \rightarrow$ TS 11} \\
\hline$X=F$ & 17.92 & 19.37 & 19.29 & 21.39 & 23.81 & 25.26 & 25.19 \\
\hline $\mathrm{X}=\mathrm{Cl}$ & 18.21 & 18.72 & 21.63 & 21.17 & 23.78 & 24.29 & 27.20 \\
\hline $\mathrm{X}=\mathrm{Br}$ & 15.86 & 15.53 & 16.17 & 18.17 & 21.66 & 21.33 & 21.97 \\
\hline
\end{tabular}


Table 5. The zero-point inclusive energy differences at $0 \mathrm{~K}, \Delta U_{0}^{\circ}$ and free-energy differences $\Delta G^{\circ}$ at $173.15 \mathrm{~K}$ with respect to reactants $\mathrm{H}_{2} \mathrm{C}=\mathrm{CH}_{2}+\mathrm{LiCH}_{3} \mathrm{X} \cdot 2 \mathrm{THF}$ for the processes summarized in Eqs. (1) and (2) (in kcal/mol).

\begin{tabular}{|c|c|c|c|c|c|c|}
\hline & $\Delta U_{0}^{\circ}$,B3LYP & $\Delta U_{0}^{\circ}, \mathrm{MP2}$ & $\begin{array}{c}\Delta U_{0}^{\circ}, \mathrm{MP2} I I \\
\text { B3LYP }\end{array}$ & $\Delta G^{\circ}, \mathrm{B} 3 \mathrm{LY}$ & $\Delta G^{\circ}, \mathrm{MP2}$ & $\begin{array}{c}\Delta G^{\circ}, \text { MP2II } \\
\text { B3LYP }\end{array}$ \\
\hline \multicolumn{7}{|c|}{$\mathrm{H}_{2} \mathrm{C}=\mathrm{CH}_{2}+\mathrm{LiCH}_{3} \mathrm{X} .2 \mathrm{THF} \rightarrow \mathrm{TS}$ 1.2THF } \\
\hline$X=F$ & 8.36 & 7.80 & 8.33 & 13.30 & 12.73 & 13.27 \\
\hline $\mathrm{X}=\mathrm{Cl}$ & 7.57 & 7.92 & 7.76 & 12.91 & 13.26 & 13.10 \\
\hline $\mathrm{X}=\mathrm{Br}$ & 5.64 & 3.82 & 3.80 & 10.26 & 8.45 & 8.42 \\
\hline \multicolumn{7}{|c|}{$\mathrm{H}_{2} \mathrm{C}=\mathrm{CH}_{2}+\mathrm{LiCH}_{3} \mathrm{X} .2 \mathrm{THF} \rightarrow \mathrm{TS}$ 2.2THF } \\
\hline$X=F$ & 13.17 & 11.40 & 9.98 & 18.58 & 16.80 & 15.38 \\
\hline $\mathrm{X}=\mathrm{Cl}$ & 17.09 & 11.89 & 12.49 & 23.05 & 17.85 & 18.45 \\
\hline $\mathrm{X}=\mathrm{Br}$ & 16.18 & 10.78 & 12.15 & 21.30 & 15.90 & 17.27 \\
\hline \multicolumn{7}{|c|}{$\mathrm{H}_{2} \mathrm{C}=\mathrm{CH}_{2}+\mathrm{LiCH}_{3} \mathrm{X} .2 \mathrm{THF} \rightarrow 3.2 \mathrm{THF}$} \\
\hline$X=F$ & -17.50 & -24.19 & -23.63 & -12.46 & -19.15 & -18.59 \\
\hline $\mathrm{X}=\mathrm{Cl}$ & -9.27 & -18.57 & -17.88 & -4.09 & -13.39 & -12.70 \\
\hline $\mathrm{X}=\mathrm{Br}$ & -9.70 & -18.26 & -17.63 & -4.75 & -13.30 & -12.68 \\
\hline \multicolumn{7}{|c|}{$\mathrm{H}_{2} \mathrm{C}=\mathrm{CH}_{2}+\mathrm{LiCH}_{3} \mathrm{X} .2 \mathrm{THF} \rightarrow$ Cyclopropane $+\mathrm{LiX} .2 \mathrm{THF}$} \\
\hline$X=F$ & -59.11 & -65.71 & -66.60 & -59.40 & -66.00 & -66.89 \\
\hline $\mathrm{X}=\mathrm{Cl}$ & -58.33 & -64.02 & -65.35 & -58.62 & -64.31 & -65.65 \\
\hline$X=B r$ & -54.59 & -62.96 & -63.44 & -55.76 & -64.13 & -64.61 \\
\hline
\end{tabular}


Table 6. The zero-point inclusive energy differences at $0 \mathrm{~K}, \Delta U_{0}^{\ddagger}$, and free-energy differences $\Delta G^{\ddagger}$ at $173.15 \mathrm{~K}$ with respect to the reactants $\mathrm{H}_{2} \mathrm{C}=\mathrm{CH}_{2}+\mathrm{LiCH}_{3} \mathrm{X} \cdot 2 \mathrm{THF}$ for the formation of TS4 and TS5 (in kcal/mol).

\begin{tabular}{|c|c|c|c|c|c|c|}
\hline & $\Delta U_{0}^{\ddagger}$, BзLYP & $\Delta U_{0}^{\ddagger}, \mathrm{MP2}$ & $\begin{array}{c}\Delta U_{0}^{\ddagger}, \text { MP2II } \\
\text { BзLYP }\end{array}$ & $\Delta G^{\ddagger}, \mathrm{B} 3 \mathrm{LYP}$ & $\Delta G^{\ddagger}, \mathrm{MP2}$ & $\begin{array}{c}\Delta G^{\ddagger}, \mathrm{MP} 2 \| \\
\text { B3LYP }\end{array}$ \\
\hline \multicolumn{7}{|c|}{ TS 4.2THF (anti), relative to $\mathrm{H}_{2} \mathrm{C}=\mathrm{CH}_{2}+\mathrm{LiCH}_{3} \mathrm{X} \cdot 2 \mathrm{THF}$} \\
\hline$X=F$ & 8.13 & 1.84 & 1.51 & 13.67 & 7.37 & 7.05 \\
\hline $\mathrm{X}=\mathrm{Cl}$ & 1.35 & -0.58 & -0.62 & 6.76 & 4.83 & 4.79 \\
\hline $\mathrm{X}=\mathrm{Br}$ & 2.03 & -3.43 & -4.06 & 6.33 & 0.87 & 0.24 \\
\hline \multicolumn{7}{|c|}{ TS 5.2THF (syn), relative to $\mathrm{H}_{2} \mathrm{C}=\mathrm{CH}_{2}+\mathrm{LiCH}_{3} \mathrm{X} \cdot 2 \mathrm{THF}$} \\
\hline$X=F$ & 8.92 & 8.92 & 9.40 & 13.77 & 13.77 & 14.25 \\
\hline $\mathrm{X}=\mathrm{Cl}$ & 12.81 & 13.80 & 15.24 & 18.34 & 19.33 & 20.77 \\
\hline $\mathrm{X}=\mathrm{Br}$ & 10.78 & 10.60 & 11.41 & 16.13 & 15.95 & 16.76 \\
\hline
\end{tabular}


Table 7. The MP2/6-31+G(d) $\Delta U_{0}^{\circ}$ and $\Delta G^{\circ}$ at $173.15 \mathrm{~K}$ for dimerization of the THF solvated halomethyllithiums, and for partial desolvation of the dimers (in $\mathrm{kcal} / \mathrm{mol}$ ).

\begin{tabular}{|c|c|c|c|c|c|c|}
\hline & $\Delta U_{\mathrm{B} 3 \mathrm{LYP}}$ & $\Delta U_{\mathrm{MP2}}$ & $\Delta U_{\mathrm{MP} 2 \| \text { B } 3 \mathrm{LYP}}$ & $\Delta G_{\mathrm{B} 3 L Y P}$ & $\Delta G_{M P 2}$ & $\begin{array}{c}\Delta G_{\mathrm{MP} 21} \\
\text { BзLYP }\end{array}$ \\
\hline & \multicolumn{6}{|c|}{$2 \mathrm{LiCH}_{2} \mathrm{X} \cdot 2 \mathrm{THF} \rightarrow 6 \cdot 4 \mathrm{THF}$} \\
\hline$X=F$ & -18.12 & -31.35 & -27.94 & -11.78 & -25.01 & -21.60 \\
\hline $\mathrm{X}=\mathrm{Cl}$ & -9.89 & -30.32 & -23.10 & -1.82 & -22.26 & -15.03 \\
\hline \multirow[t]{2}{*}{$\mathrm{X}=\mathrm{Br}$} & -20.87 & -36.72 & -34.81 & -13.68 & -29.53 & -27.63 \\
\hline & \multicolumn{6}{|c|}{$2 \mathrm{LiCH}_{2} \mathrm{X} \cdot 2 \mathrm{THF} \rightarrow 7 \cdot 4 \mathrm{THF}$} \\
\hline$X=F$ & -17.16 & -30.67 & -27.14 & -9.73 & -23.24 & -19.71 \\
\hline $\mathrm{X}=\mathrm{Cl}$ & -9.54 & -29.92 & -26.44 & -0.32 & -20.71 & -17.22 \\
\hline \multirow[t]{2}{*}{$\mathrm{X}=\mathrm{Br}$} & -19.90 & -39.25 & -37.88 & -11.60 & -30.95 & -29.57 \\
\hline & \multicolumn{6}{|c|}{$6 \cdot 4 \mathrm{THF} \rightarrow 6 \cdot 3 \mathrm{THF}+\mathrm{THF}$} \\
\hline$X=F$ & 3.54 & 14.21 & 11.61 & -2.21 & 8.46 & 5.86 \\
\hline $\mathrm{X}=\mathrm{Cl}$ & 1.38 & 16.76 & 9.64 & -5.08 & 10.29 & 3.17 \\
\hline \multirow[t]{2}{*}{$\mathrm{X}=\mathrm{Br}$} & 8.59 & 18.86 & 19.05 & 1.05 & 11.32 & 11.51 \\
\hline & \multicolumn{6}{|c|}{ 7•4THF $\rightarrow$ 7.3THF+ THF } \\
\hline$X=F$ & 2.67 & 14.03 & 13.08 & -3.77 & 7.58 & 6.63 \\
\hline $\mathrm{X}=\mathrm{Cl}$ & 3.33 & 18.05 & 14.04 & -3.28 & 11.43 & 7.42 \\
\hline $\mathrm{X}=\mathrm{Br}$ & 6.83 & 17.37 & 17.44 & -0.04 & 10.49 & 10.57 \\
\hline
\end{tabular}


Table 8. The MP2/6-31+G(d) zero-point inclusive energy differences at $0 \mathrm{~K}, \Delta U_{0}^{\ddagger}$, and free-energy differences $\Delta G^{\ddagger}$ at $173.15 \mathrm{~K}$ with respect to the reactants $\mathrm{H}_{2} \mathrm{C}=\mathrm{CH}_{2}+$ $\left(\mathrm{LiCH}_{3} \mathrm{X}\right)_{2} \cdot 4 \mathrm{THF}$ for the formation of TS8-3THF and TS9·3THF (from 6.4THF) and TS10·3THF and TS11·3THF (from 7•4THF) (in kcal $/ \mathrm{mol}$ ).

\begin{tabular}{l|llll|llll}
\hline \hline & \multicolumn{4}{|c|}{$\Delta U_{0}^{\ddagger}$} & \multicolumn{4}{c}{$\Delta G^{\ddagger}$} \\
\cline { 2 - 9 } & TS 8 & TS 9 & TS 10 & TS 11 & TS 8 & TS 9 & TS 10 & TS 11 \\
\hline$X=F$ & 19.76 & 19.26 & 33.46 & 32.55 & 17.85 & 17.21 & 32.68 & 31.69 \\
$X=\mathrm{Cl}$ & 20.99 & 23.39 & 37.82 & 32.44 & 19.02 & 21.27 & 36.46 & 30.83 \\
$\mathrm{X}=\mathrm{Br}$ & 16.19 & 19.22 & 31.07 & 32.37 & 13.87 & 16.64 & 29.59 & 30.43 \\
\hline
\end{tabular}


Table 9. The MP2/6-31+G(d) zero-point inclusive energy differences at $0 \mathrm{~K}, \Delta U_{0}^{\circ}$ and free-energy differences $\Delta G^{\circ}$ at $173.15 \mathrm{~K}$ with respect to $\mathrm{H}_{2} \mathrm{C}=\mathrm{CH}_{2}+\left(\mathrm{LiCH}_{3} \mathrm{X}\right)_{2} \cdot 4 \mathrm{THF}$ for the formation of THF-solvated 3-halopropyllithium, as shown in Eq. (11) (in $\mathrm{kcal} / \mathrm{mol})$.

\begin{tabular}{l|cc|cc}
\hline \hline \multirow{2}{*}{} & \multicolumn{2}{|c|}{$\Delta U_{0}^{\circ}$, MP2 } & \multicolumn{2}{c}{$\Delta G^{\circ}{ }_{\text {,MP2 }}$} \\
\cline { 2 - 5 } & $\mathbf{6}$ & $\mathbf{7}$ & $\mathbf{6}$ & $\mathbf{7}$ \\
\hline $\mathrm{X}=\mathrm{F}$ & 7.16 & 6.48 & 5.86 & 5.00 \\
$\mathrm{X}=\mathrm{Cl}$ & 11.75 & 11.36 & 8.87 & 8.23 \\
$\mathrm{X}=\mathrm{Br}$ & 18.46 & 20.99 & 16.23 & 18.56 \\
\hline
\end{tabular}


Table 10. The zero-point inclusive energy differences at $0 \mathrm{~K}, \Delta U_{0}^{\circ}$ and free-energy differences $\Delta G^{\circ}$ at $173.15 \mathrm{~K}$ with respect to reactants for the processes summarized in Eqs. (12)-(14) (in kcal/mol).

\begin{tabular}{|c|c|c|c|c|c|c|}
\hline & $\Delta U_{0}^{\circ}$, ВзLYP & $\Delta U_{0}^{\circ}, \mathrm{MP2}$ & $\begin{array}{c}\Delta U_{0}^{\circ}, \text { MP2II } \\
\text { B3LYP } \\
\end{array}$ & $\Delta G^{\circ}, \mathrm{B} 3 \mathrm{LYP}$ & $\Delta G^{\circ}, \mathrm{MP2}$ & $\begin{array}{c}\Delta G^{\circ}, \text { MP2II } \\
\text { B3LYP }\end{array}$ \\
\hline \multicolumn{7}{|c|}{$26 \rightarrow\left(\mathrm{LiCH}_{3} \mathrm{X}\right)_{4}$} \\
\hline$X=F$ & -27.93 & -31.92 & -32.17 & -19.59 & -23.58 & -23.83 \\
\hline $\mathrm{X}=\mathrm{Cl}$ & -25.30 & -37.97 & -38.29 & -16.70 & -29.37 & -29.69 \\
\hline $\mathrm{X}=\mathrm{Br}$ & -36.34 & -48.30 & -48.43 & -28.02 & -39.99 & -40.12 \\
\hline \multicolumn{7}{|c|}{$\left(\mathrm{LiCH}_{3} \mathrm{X}\right)_{4}+\mathrm{H}_{2} \mathrm{C}=\mathrm{CH}_{2} \rightarrow$ concerted TS 12} \\
\hline$X=F$ & 4.53 & 3.58 & 3.70 & 8.07 & 7.11 & 7.24 \\
\hline $\mathrm{X}=\mathrm{Cl}$ & 9.67 & 11.50 & 11.81 & 14.74 & 16.57 & 16.89 \\
\hline $\mathrm{X}=\mathrm{Br}$ & 3.22 & 2.53 & 2.72 & 8.82 & 8.14 & 8.32 \\
\hline \multicolumn{7}{|c|}{$\left(\mathrm{LiCH}_{3} \mathrm{X}\right)_{4}+\mathrm{H}_{2} \mathrm{C}=\mathrm{CH}_{2} \rightarrow$ stepwise TS 13} \\
\hline$X=F$ & 30.94 & 31.77 & 31.95 & 36.23 & 37.06 & 37.23 \\
\hline $\mathrm{X}=\mathrm{Cl}$ & 28.58 & 29.79 & 30.09 & 34.26 & 35.47 & 35.77 \\
\hline $\mathrm{X}=\mathrm{Br}$ & 26.61 & 26.03 & 26.04 & 32.82 & 32.24 & 32.25 \\
\hline
\end{tabular}


Table 11. The zero-point inclusive energy differences at $0 \mathrm{~K}, \Delta U_{0}^{\circ}$ and free-energy differences $\Delta G^{\circ}$ at $173.15 \mathrm{~K}$ with respect to reactants for the tetramerization in Eq. (15) (in kcal/mol).

\begin{tabular}{|c|c|c|c|c|c|c|}
\hline & $\Delta U_{0}^{\circ}$, ВзLYP & $\Delta U_{0}^{\circ}, \mathrm{MP2}$ & $\begin{array}{c}\Delta U_{0}^{\circ}, \mathrm{MP} 2 \| l \\
\text { B3LYP } \\
\end{array}$ & $\Delta G^{\circ}, \mathrm{B} 3 L Y \mathrm{P}$ & $\Delta G^{\circ}, \mathrm{MP2}$ & $\begin{array}{c}\Delta G^{\circ}, \text { MP2II } \\
\text { B3LYP }\end{array}$ \\
\hline \multicolumn{7}{|c|}{2 6.4THF $\rightarrow\left(\mathrm{LiCH}_{3} \mathrm{X}\right)_{4} .4 \mathrm{THF}+4 \mathrm{THF}$} \\
\hline$X=F$ & 4.48 & 26.64 & 21.98 & -10.75 & 11.40 & 6.75 \\
\hline $\mathrm{X}=\mathrm{Cl}$ & 11.38 & 27.11 & 14.51 & -5.70 & 10.03 & -2.57 \\
\hline $\mathrm{X}=\mathrm{Br}$ & 10.86 & 19.32 & 17.14 & -6.70 & 1.76 & -0.42 \\
\hline
\end{tabular}


Table 12. The free-energy differences $\Delta G^{\circ}$ at $173.15 \mathrm{~K}$ with respect to reactants for the tetramerization in Eq. (12) taking solvent effects into account through a continuum solvation model (in $\mathrm{kcal} / \mathrm{mol}$ ).

\begin{tabular}{|c|c|c|c|c|c|}
\hline & $\Delta G_{\mathrm{MP2}}$ (gas) $^{\mathrm{a}}$ & $\Delta G_{P C M}(6)^{b}$ & $\Delta G_{P C M}(\text { tet })^{b}$ & Std. State ${ }^{c}$ & $\Delta G_{\mathrm{MP} 2(\mathrm{PCM})}$ \\
\hline$X=F$ & -23.58 & -3.16 & -0.97 & -1.83 & -20.07 \\
\hline $\mathrm{X}=\mathrm{Cl}$ & -29.37 & -0.27 & 3.43 & -1.83 & -27.23 \\
\hline $\mathrm{X}=\mathrm{Br}$ & -39.99 & -0.37 & 3.47 & -1.83 & -37.61 \\
\hline
\end{tabular}

${ }^{\text {a }}$ From Table 10.

${ }^{\mathrm{b}} \mathrm{HF} / 6-31+\mathrm{G}(\mathrm{d})$ with UAHF radii, $\varepsilon=7.85$

${ }^{c}$ Correction for changing standard state from $1 \mathrm{~atm}$ at $173.15 \mathrm{~K}$ to $1 \mathrm{~mol} / \mathrm{L}$. 
Table 13. The $\Delta U_{0}^{\circ}$ and $\Delta G^{\circ}$ at $173.15 \mathrm{~K}$ for the reactions of the gas phase dimers 6 and 7 (in $\mathrm{kcal} / \mathrm{mol}$ ) with 2,3-dimethyl-2-butene.

\begin{tabular}{|c|c|c|c|c|c|c|}
\hline & $\Delta U_{0}^{\circ}$,В3LYP & $\Delta U_{0}^{\circ}, \mathrm{MP2}$ & $\begin{array}{c}\Delta U_{0}^{\circ}, \mathrm{MP2} 21 \\
\text { B3LYP } \\
\end{array}$ & $\Delta G^{\circ}, \mathrm{B} 3 L Y \mathrm{P}$ & $\Delta G^{\circ}, \mathrm{MP2}$ & $\begin{array}{c}\Delta G^{\circ}, \text { MP2II } \\
\text { B3LYP }\end{array}$ \\
\hline \multicolumn{7}{|c|}{$\left(\mathrm{CH}_{3}\right)_{2} \mathrm{C}=\mathrm{C}\left(\mathrm{CH}_{3}\right)_{2}+\mathbf{6} \rightarrow \mathrm{TS} 14$} \\
\hline$X=F$ & 6.08 & 2.75 & 3.13 & 12.14 & 8.80 & 9.19 \\
\hline $\mathrm{X}=\mathrm{Cl}$ & 8.21 & 4.21 & 6.81 & 13.67 & 9.67 & 12.27 \\
\hline $\mathrm{X}=\mathrm{Br}$ & 5.79 & 1.99 & 2.52 & 13.32 & 9.52 & 10.06 \\
\hline \multicolumn{7}{|c|}{$\left(\mathrm{CH}_{3}\right)_{2} \mathrm{C}=\mathrm{C}\left(\mathrm{CH}_{3}\right)_{2}+\mathbf{6} \rightarrow \mathbf{1 6}^{\prime}$} \\
\hline$X=F$ & -6.89 & -12.45 & -11.82 & -1.23 & -6.78 & -6.16 \\
\hline $\mathrm{X}=\mathrm{Cl}$ & -5.94 & -13.58 & -12.77 & 0.21 & -7.43 & -6.61 \\
\hline $\mathrm{X}=\mathrm{Br}$ & -8.90 & -16.86 & -15.75 & -2.51 & -10.46 & -9.36 \\
\hline \multicolumn{7}{|c|}{$\left(\mathrm{CH}_{3}\right)_{2} \mathrm{C}=\mathrm{C}\left(\mathrm{CH}_{3}\right)_{2}+\mathbf{6} \rightarrow \mathrm{TS} 16$} \\
\hline$X=F$ & 33.39 & 27.40 & 28.23 & 40.31 & 34.32 & 35.15 \\
\hline $\mathrm{X}=\mathrm{Cl}$ & 39.18 & 29.39 & 30.68 & 46.89 & 37.10 & 38.38 \\
\hline $\mathrm{X}=\mathrm{Br}$ & 30.39 & 21.12 & 22.12 & 38.43 & 29.15 & 30.16 \\
\hline \multicolumn{7}{|c|}{$\left(\mathrm{CH}_{3}\right)_{2} \mathrm{C}=\mathrm{C}\left(\mathrm{CH}_{3}\right)_{2}+7 \rightarrow \mathrm{TS} 15$} \\
\hline$X=F$ & 4.81 & 0.95 & 1.19 & 11.07 & 7.21 & 7.45 \\
\hline $\mathrm{X}=\mathrm{Cl}$ & 4.44 & 2.06 & 2.08 & 9.87 & 7.50 & 7.51 \\
\hline $\mathrm{X}=\mathrm{Br}$ & 2.63 & -1.68 & -1.19 & 8.90 & 4.59 & 5.08 \\
\hline \multicolumn{7}{|c|}{$\left(\mathrm{CH}_{3}\right)_{2} \mathrm{C}=\mathrm{C}\left(\mathrm{CH}_{3}\right)_{2}+\mathbf{7} \rightarrow \mathbf{1 7}^{\prime}$} \\
\hline$X=F$ & -7.63 & -13.42 & -12.92 & -0.66 & -6.45 & -5.96 \\
\hline $\mathrm{X}=\mathrm{Cl}$ & -7.58 & -15.27 & -14.29 & -1.42 & -9.11 & -8.12 \\
\hline $\mathrm{X}=\mathrm{Br}$ & -9.44 & -17.27 & -17.03 & -2.69 & -10.51 & -10.28 \\
\hline \multicolumn{7}{|c|}{$\left(\mathrm{CH}_{3}\right)_{2} \mathrm{C}=\mathrm{C}\left(\mathrm{CH}_{3}\right)_{2}+7 \rightarrow \mathrm{TS} 17$} \\
\hline$X=F$ & 32.28 & 26.58 & 27.22 & 39.66 & 33.97 & 34.60 \\
\hline $\mathrm{X}=\mathrm{Cl}$ & 34.18 & 24.84 & 26.19 & 41.43 & 32.10 & 33.45 \\
\hline $\mathrm{X}=\mathrm{Br}$ & 28.39 & 19.18 & 20.52 & 36.07 & 26.86 & 28.20 \\
\hline
\end{tabular}




\section{Figure Captions}

1. The MP2/6-31+G(d) intrinsic reaction coordinate (IRC) in $(\mathrm{amu})^{1 / 2}$ bohr for the concerted reaction and the first step of the stepwise mechanism for the gas phase monomer $\mathrm{LiCH}_{2} \mathrm{Br}$. All energies are relative to the asymptotic reactants. The point $\mathrm{B}$ is at an energy of -27.9 $\mathrm{kcal} / \mathrm{mol}$, at reaction coordinate value of 2.99 . Solid lines with symbols are based on IRC calculations while the dashed lines are "physically reasonable" interpolations through available data. The zero of the energy axis represents the reactants at infinite separation.

2. The structures corresponding to the labeled points on the IRC's shown in Figure 1 for $\mathrm{LiCH}_{2} \mathrm{X}, \mathrm{X}=\mathrm{Br}$. The corresponding structures for $\mathrm{X}=\mathrm{F}$ and $\mathrm{Cl}$ are similar.

3. The B3LYP/6-31+G(d) IRC's in (amu) ${ }^{1 / 2}$ bohr for the anti (solid symbols) and syn (open symbols) elimination of $\mathrm{LiCl}$ from the intermediate $\mathrm{Li}-\left(\mathrm{CH}_{2}\right)_{3}-\mathrm{Cl}$. All energies are relative to asymptotic reactants $\mathrm{H}_{2} \mathrm{C}=\mathrm{CH}_{2}+\mathrm{LiCH}_{2} \mathrm{Cl}$. Point $\mathrm{I}$ is at $E_{\text {rel }}=-31.6 \mathrm{kcal} / \mathrm{mol}$ at reaction coordinate value of 3.96 .

4. The structures corresponding to the labeled points on the B3LYP/6-31+G(d) IRC's shown in Figure 3 for $\mathrm{LiCH}_{2} \mathrm{Cl}$. The corresponding structures for $\mathrm{X}=\mathrm{F}$ and $\mathrm{Cl}$ are similar. Bond lengths shown are in Angstroms.

5. The MP2/6-31+G(d) IRC in $(\mathrm{amu})^{1 / 2}$ bohr for the concerted and stepwise reactions of gas phase dimers of $\mathrm{LiCH}_{2} \mathrm{Br}$. All energies are relative to the asymptotic reactants $\mathrm{H}_{2} \mathrm{C}=\mathrm{CH}_{2}+$ $\mathrm{LiCH}_{2} \mathrm{Br}$. (a) IRC's of dimer 6. The point $\mathrm{B}$ is at an energy of $-13.8 \mathrm{kcal} / \mathrm{mol}$, at reaction coordinate value of 2.97. (b) IRC's of dimer 7. The point B is at an energy of $-15.2 \mathrm{kcal} / \mathrm{mol}$, at reaction coordinate value of 2.69. The significance of the dashed lines are the same as in Figure 1. The zero of the energy axis represents the reactants at infinite separation.

6. The structures corresponding to the labeled points on the IRC's of dimer $\mathbf{6}$ shown in Figure 5(a) for $\mathrm{LiCH}_{2} \mathrm{X}, \mathrm{X}=\mathrm{Br}$. The corresponding structures for $\mathrm{X}=\mathrm{F}$ and $\mathrm{Cl}$ are similar. Bond lengths shown are in Angstroms.

7. The structures corresponding to the labeled points on the IRC's of dimer $\mathbf{7}$ shown in Figure 5(b), for $\mathrm{LiCH}_{2} \mathrm{X}, \mathrm{X}=\mathrm{Br}$. Structures for $\mathrm{X}=\mathrm{F}$ and $\mathrm{Cl}$ are similar. Bond lengths shown are in Angstroms.

8. Equilibrium structures of $\mathbf{6} \bullet 4 \mathrm{THF}$ for $\mathrm{X}=\mathrm{F}$ obtained from (a) B3LYP/6-31+G(d) starting with the $\mathrm{HF} / 6-31+\mathrm{G}(d)$ equilibrium structure, (b) MP2/6-31+G(d) starting with the structure in panel (a), and (c) the B3LYP/6-31+G(d) structure obtained from the structure in panel (b). Hydrogens are not shown for clarity.

9. MP2 free energy profiles of the reactions of the (a) THF-solvated monomer and (b) dimer 6 with ethylene. The energy levels are color-coded based on $\mathrm{X}$ : blue $(\mathrm{F})$, green $(\mathrm{Cl})$, and red (Br). The lines connect the average energy of the three derivatives of each species. All energies are relative to the reactants. For clarity, the products LiX + cyclopropane, which are at very large negative values, are not shown.

10. The MP2/6-31+G(d) structures of the tetramer, the transition state for the concerted (TS 12) and stepwise (TS 13) reactions for the case $\mathrm{X}=\mathrm{F}$.

11. Upper panels: The MP2/6-31+G(d) transition states for the concerted reactions of dimer 6 (TS 14) and dimer 7 (TS 15) with 2,3-dimethylbutene for the case $X=B r$. Lower panels: The 
MP2/6-31+G(d) structures of the pre-reactive complex $\mathbf{1 6}^{\prime}$ and TS $\mathbf{1 6}$ for dimer $\mathbf{6}$, and the pre-reactive complex 17' and TS 17 for dimer 7 for the stepwise reactions with 2,3dimethylbutene for the case $\mathrm{X}=\mathrm{Br}$. Hydrogens are not shown for clarity.

12. MP2/6-31+G(d) structures of TS 14 (top row) and TS 15 (bottom row) showing Merz-SinghKollman charges and Li-C distances in Angstroms. Left: $\mathrm{LiCH}_{2} \mathrm{~F}$; Center: $\mathrm{LiCH}_{2} \mathrm{Cl}$; Right: $\mathrm{LiCH}_{2} \mathrm{Br}$. The stronger interaction in TS 15 for $\mathrm{X}=\mathrm{Br}$ leads to a weakly bound pre-reactive complex in the intrinsic reaction coordinate and a negative reaction barrier relative to reactants.

13. MP2/6-31+G(d) IRC's in $(\mathrm{amu})^{1 / 2}$ bohr for dimers $\mathbf{6}$ and $\mathbf{7}$ for $\mathrm{X}=\mathrm{Cl}$ and $\mathrm{Br}$ reacting with dimethylbutene. The symbols connected by solid lines indicate the extent to which IRC calculations could be converged. The dashed lines are "physically reasonable" spline interpolations reach zero energy at -10 . The zero of the energy axis represents the reactants at infinite separation. 


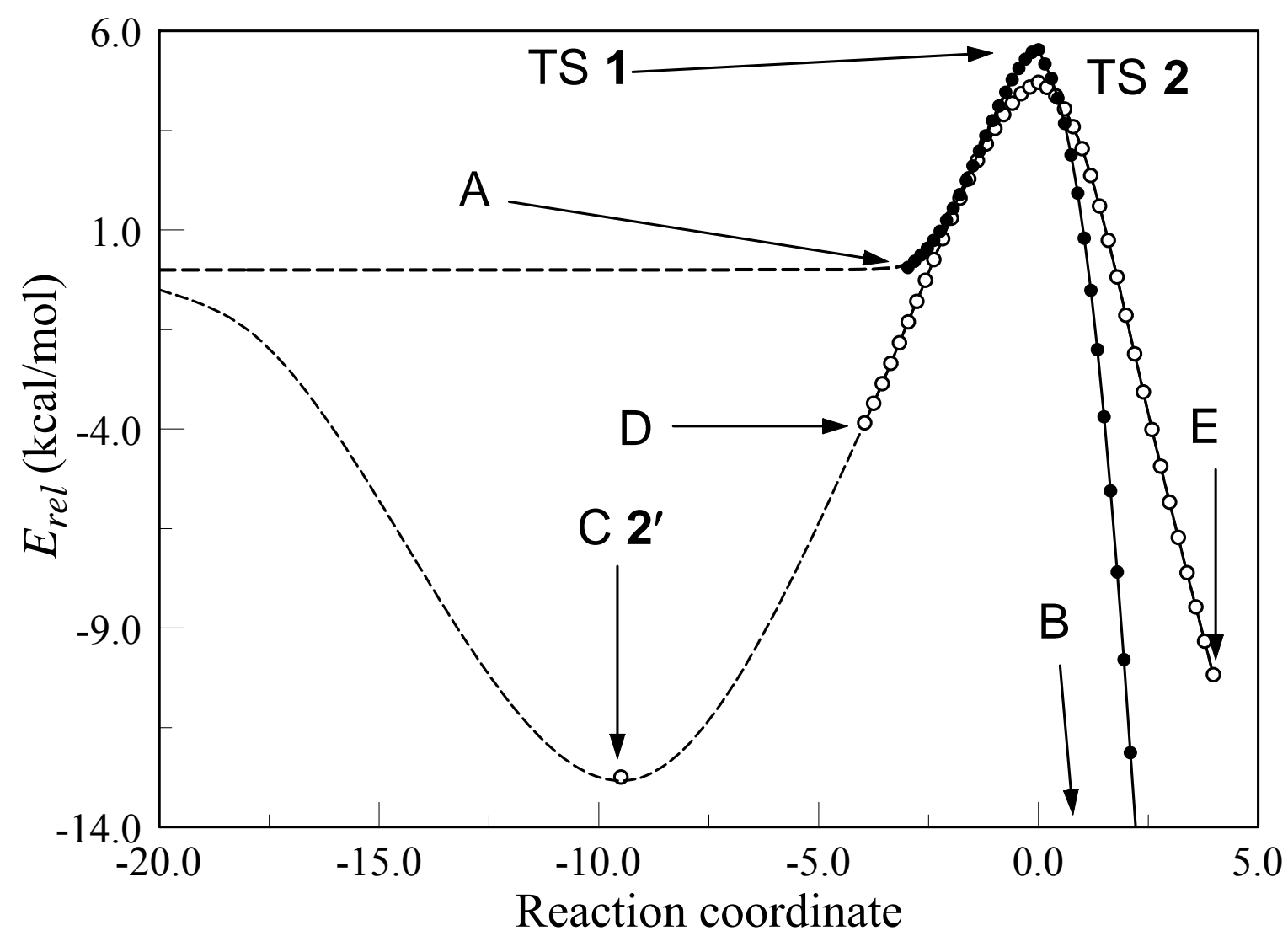

Figure 1. The MP2/6-31+G(d) intrinsic reaction coordinate (IRC)in (amu) ${ }^{1 / 2}$ bohr for the concerted reaction and the first step of the stepwise mechanism for the gas phase monomer $\mathrm{LiCH}_{2} \mathrm{Br}$. All energies are relative to the asymptotic reactants. The point $\mathrm{B}$ is at an energy of $27.9 \mathrm{kcal} / \mathrm{mol}$, at reaction coordinate value of 2.99 . Solid lines with symbols are based on IRC calculations while the dashed lines are "physically reasonable" interpolations through available data. The zero of the energy axis represents the reactants at infinite separation. 

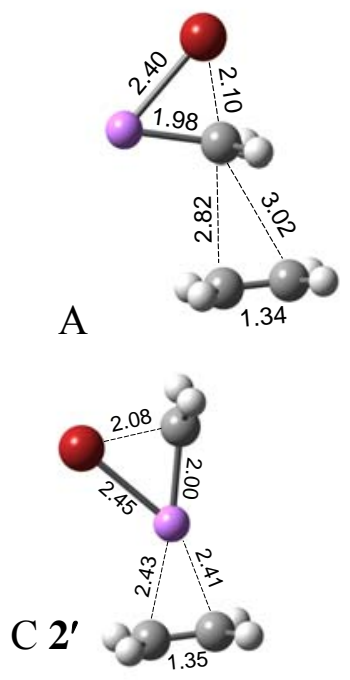

TS 1

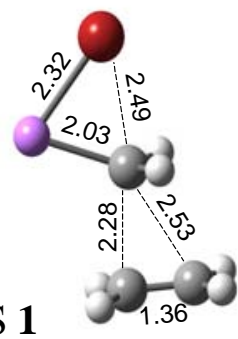

D

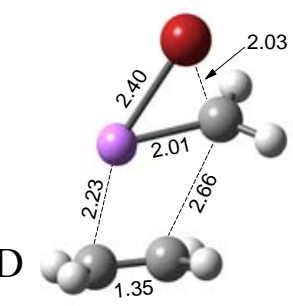

TS 2

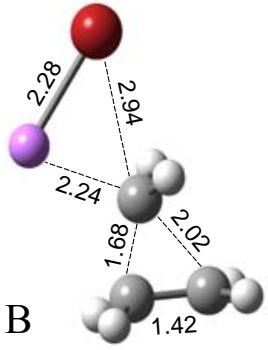

Figure 2. The structures corresponding to the labeled points on the IRC's shown in Figure 1 for $\mathrm{LiCH}_{2} \mathrm{X}, \mathrm{X}=\mathrm{Br}$. Distances are in Angstroms. The corresponding structures for $\mathrm{X}=\mathrm{F}$ and $\mathrm{Cl}$ are similar. 


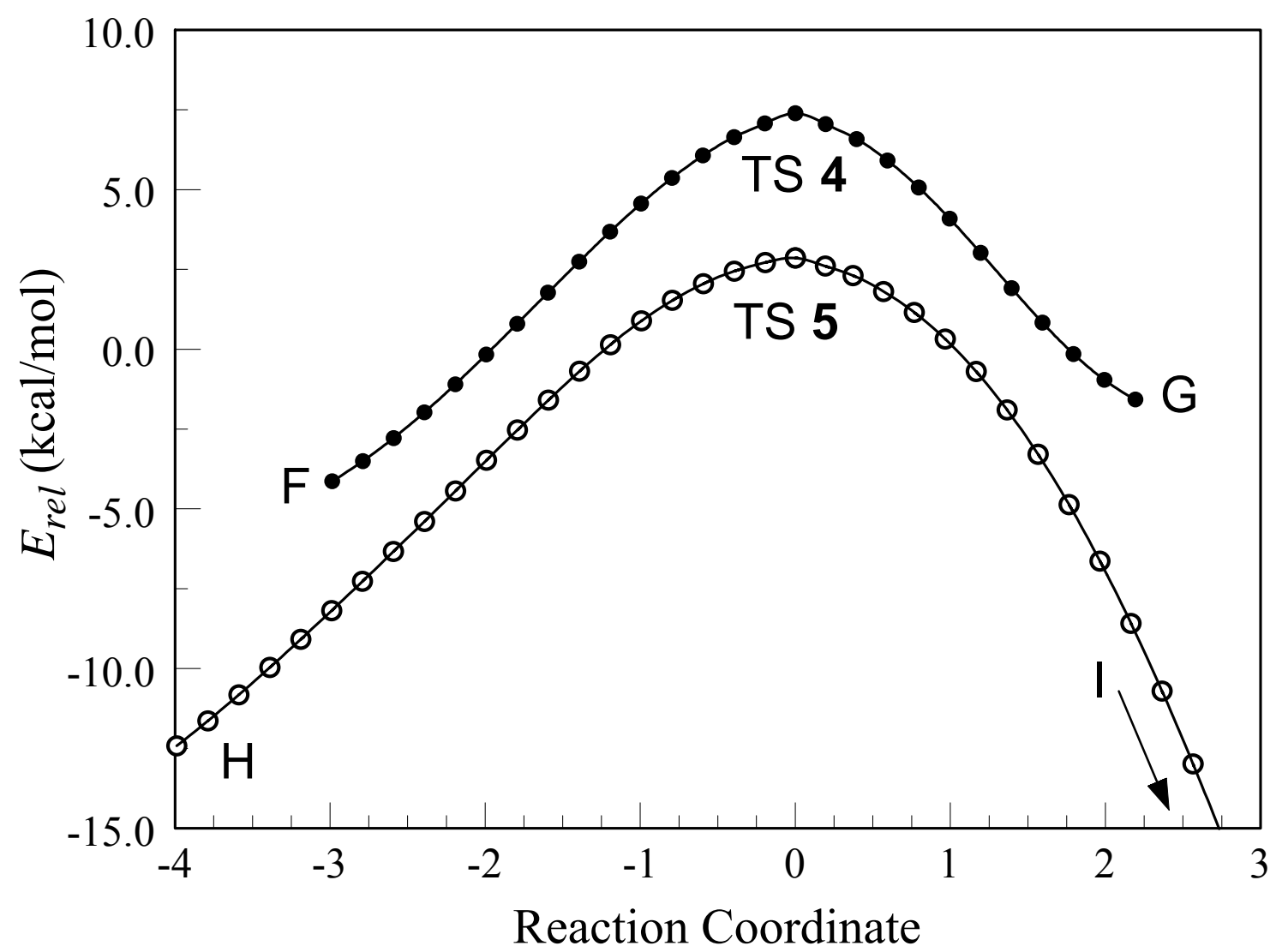

Figure 3. The B3LYP/6-31+G(d) IRC's in (amu $)^{1 / 2}$ bohr for the anti (solid symbols) and syn (open symbols) elimination of $\mathrm{LiCl}$ from the intermediate $\mathrm{Li}-\left(\mathrm{CH}_{2}\right)_{3}-\mathrm{Cl}$. All energies are relative to asymptotic reactants $\mathrm{H}_{2} \mathrm{C}=\mathrm{CH}_{2}+\mathrm{LiCH}_{2} \mathrm{Cl}$. Point $\mathrm{I}$ is at $E_{\text {rel }}=-31.6 \mathrm{kcal} / \mathrm{mol}$ at reaction coordinate value of 3.96 . 

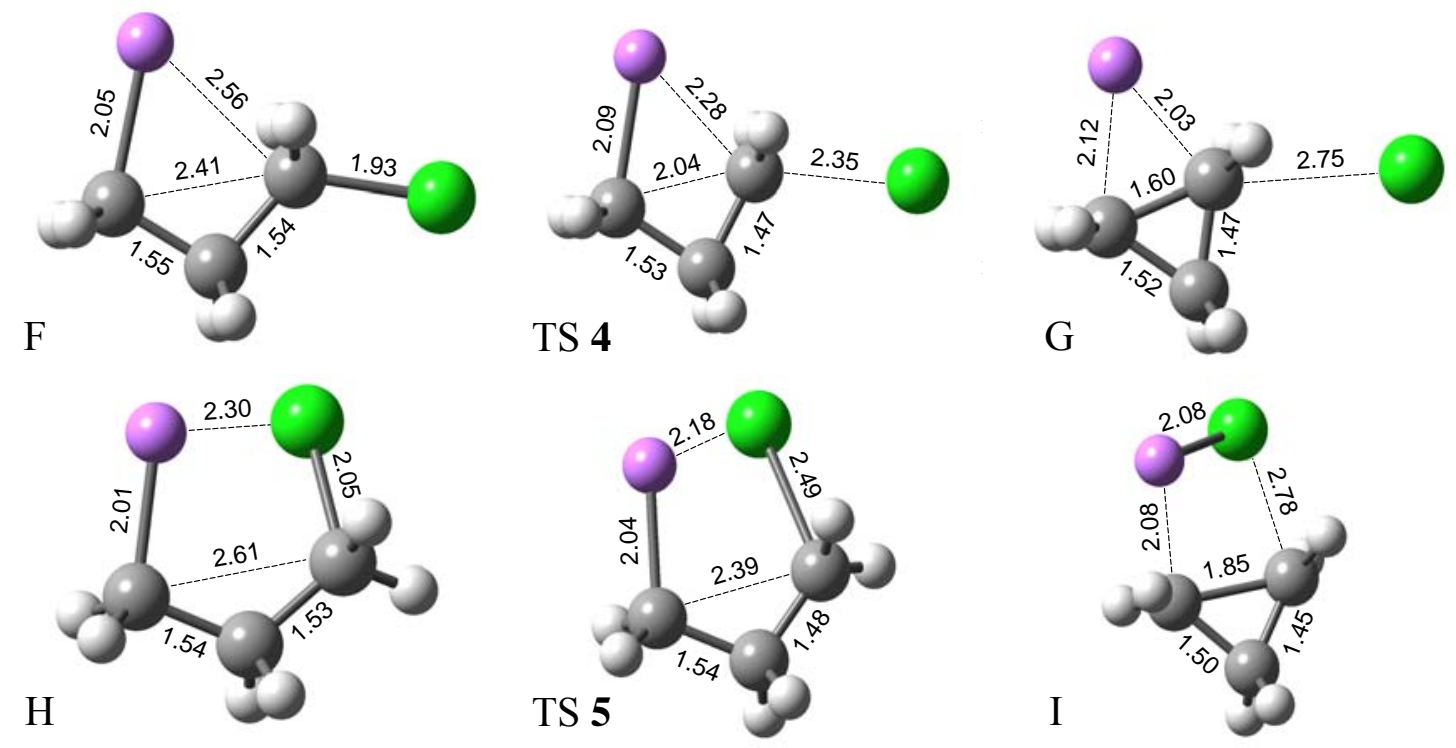

Figure 4. The structures corresponding to the labeled points on the B3LYP/6-31+G(d) IRC's shown in Figure 3 for $\mathrm{LiCH}_{2} \mathrm{Cl}$. Distances are in Angstroms. The corresponding structures for $\mathrm{X}=\mathrm{F}$ and $\mathrm{Cl}$ are similar. Bond lengths shown are in Angstroms. 
(a)

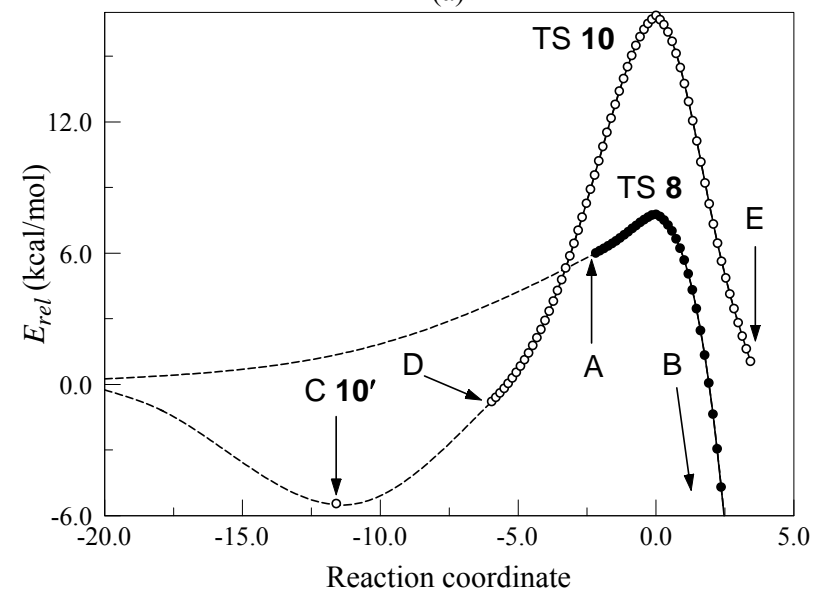

(b)

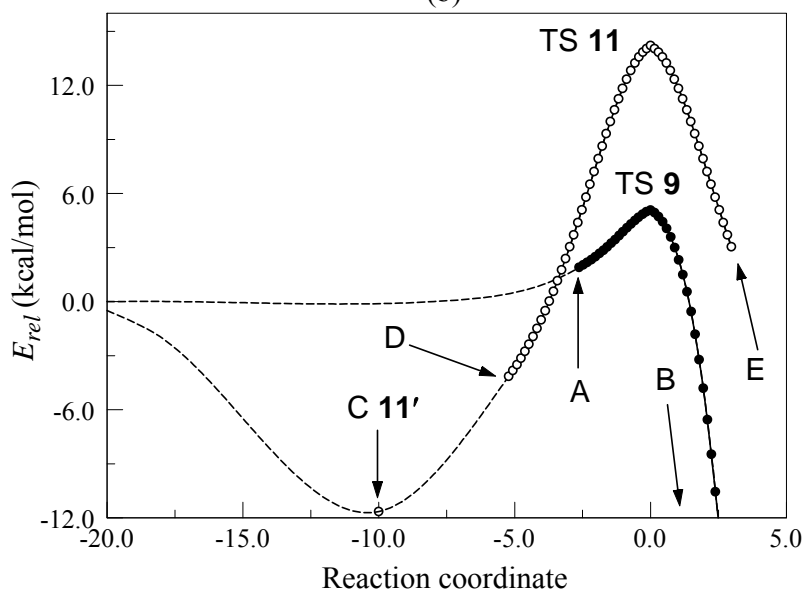

Figure 5. The MP2/6-31+G(d) IRC in $(\mathrm{amu})^{1 / 2}$ bohr for the concerted and stepwise reactions of gas phase dimers of $\mathrm{LiCH}_{2} \mathrm{Br}$. All energies are relative to the asymptotic reactants $\mathrm{H}_{2} \mathrm{C}=\mathrm{CH}_{2}+$ $\mathrm{LiCH}_{2} \mathrm{Br}$. (a) IRC's of dimer 6. The point $\mathrm{B}$ is at an energy of $-13.8 \mathrm{kcal} / \mathrm{mol}$, at reaction coordinate value of 2.97. (b) IRC's of dimer 7. The point B is at an energy of $-15.2 \mathrm{kcal} / \mathrm{mol}$, at reaction coordinate value of 2.69. The significance of the dashed lines are the same as in Figure 1. The zero of the energy axis represents the reactants at infinite separation. 

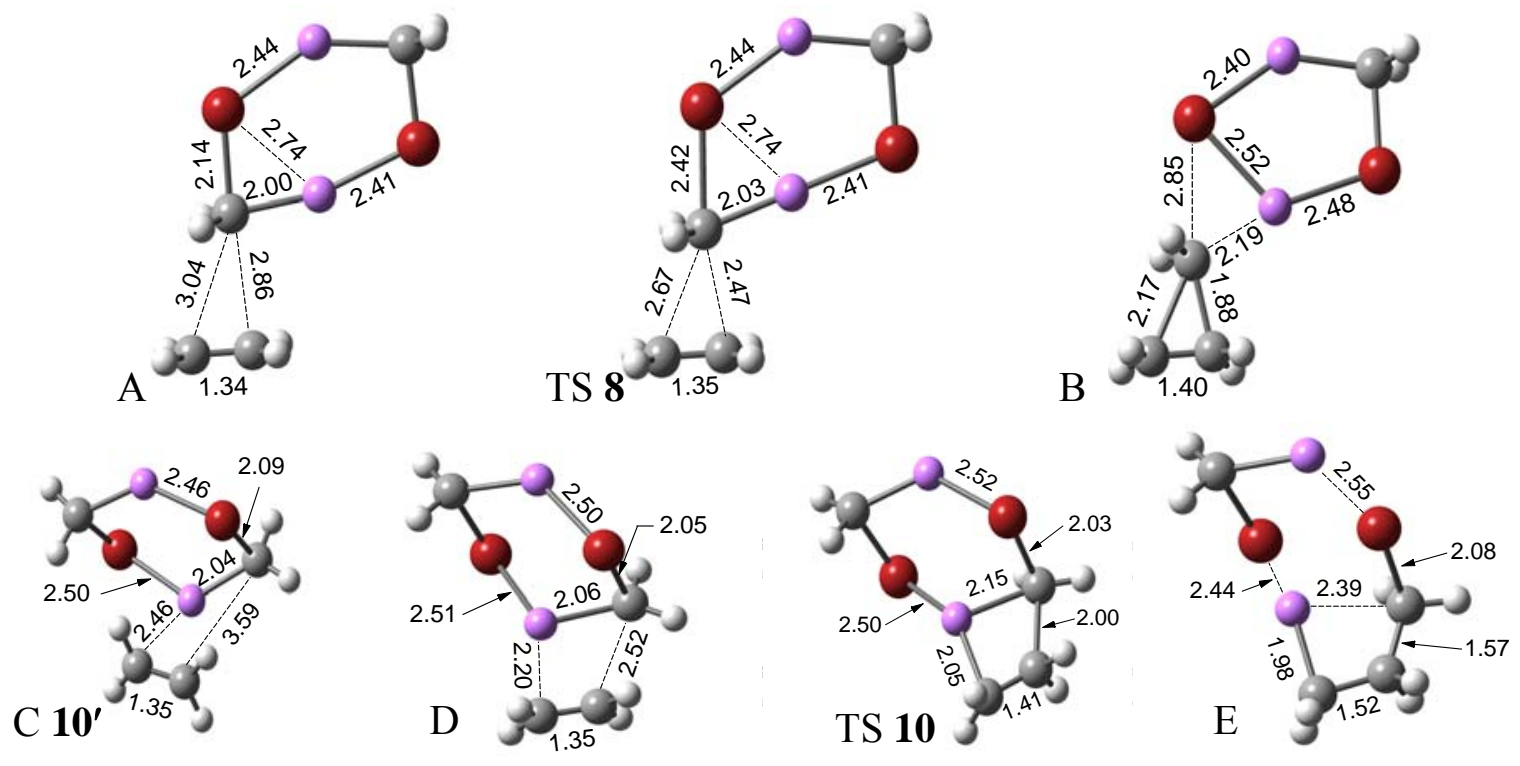

Figure 6. The structures corresponding to the labeled points on the IRC's of dimer 6 shown in Figure 5(a) for $\mathrm{LiCH}_{2} \mathrm{X}, \mathrm{X}=\mathrm{Br}$. The corresponding structures for $\mathrm{X}=\mathrm{F}$ and $\mathrm{Cl}$ are similar. Bond lengths shown are in Angstroms. 

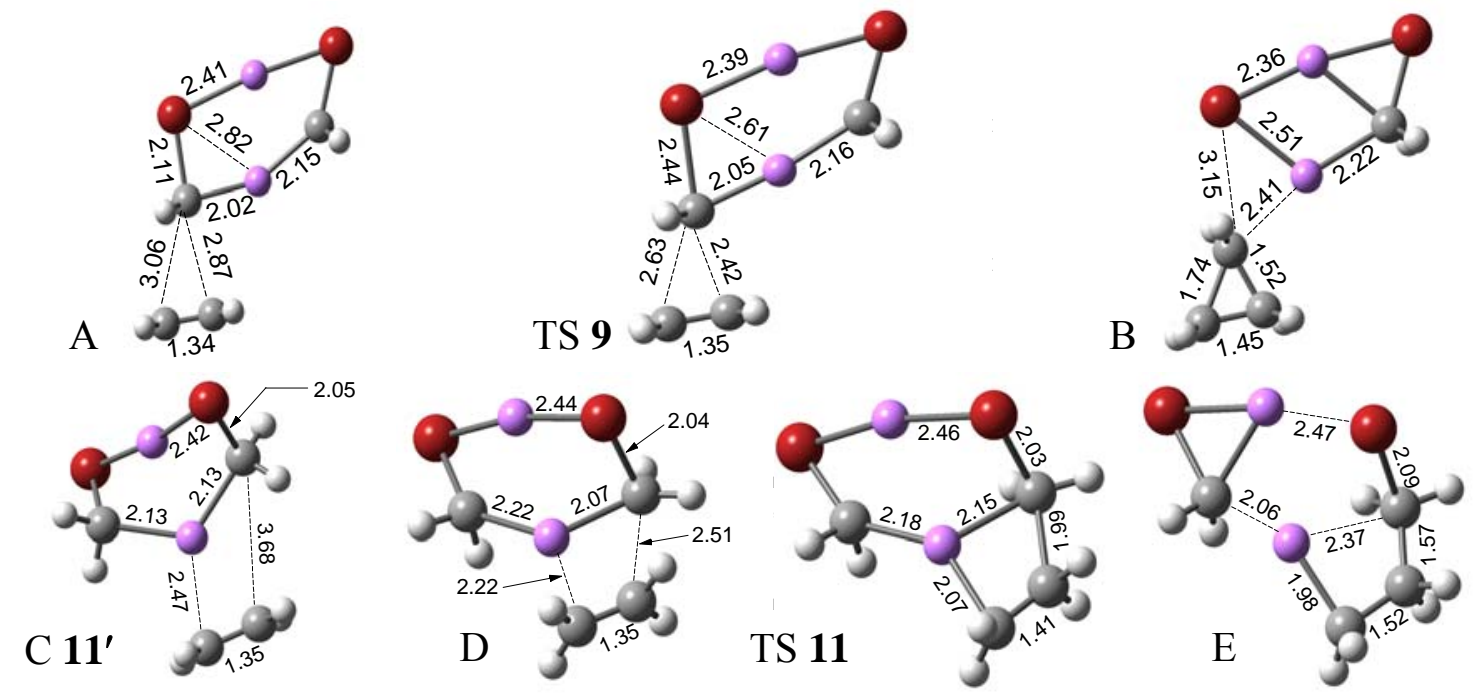

Figure 7. The structures corresponding to the labeled points on the IRC's of dimer 7 shown in Figure 5(b), for $\mathrm{LiCH}_{2} \mathrm{X}, \mathrm{X}=\mathrm{Br}$. Structures for $\mathrm{X}=\mathrm{F}$ and $\mathrm{Cl}$ are similar. Bond lengths shown are in Angstroms. 
(a)

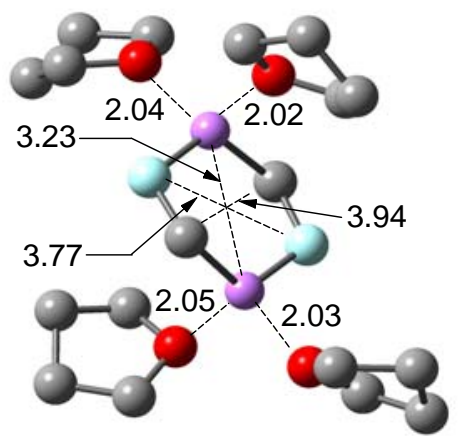

(b)

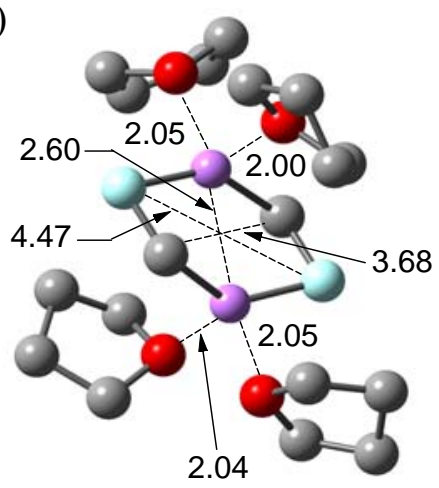

(c)

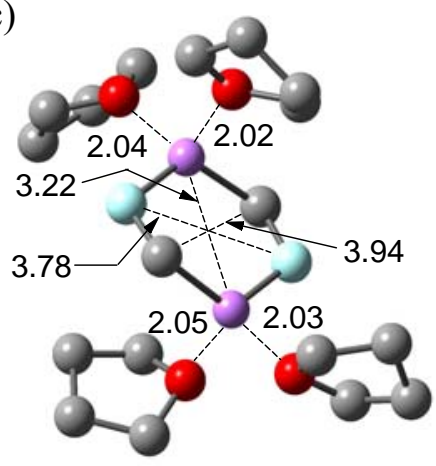

Figure 8. Equilibrium structures of 6•4THF for $X=F$ obtained from (a) B3LYP/6-31+G(d) starting with the HF/6-31+G(d) equilibrium structure, (b) MP2/6-31+G(d) starting with the structure in panel (a), and (c) the B3LYP/6-31+G(d) structure obtained from the structure in panel (b). Hydrogens are not shown for clarity. 
(a)

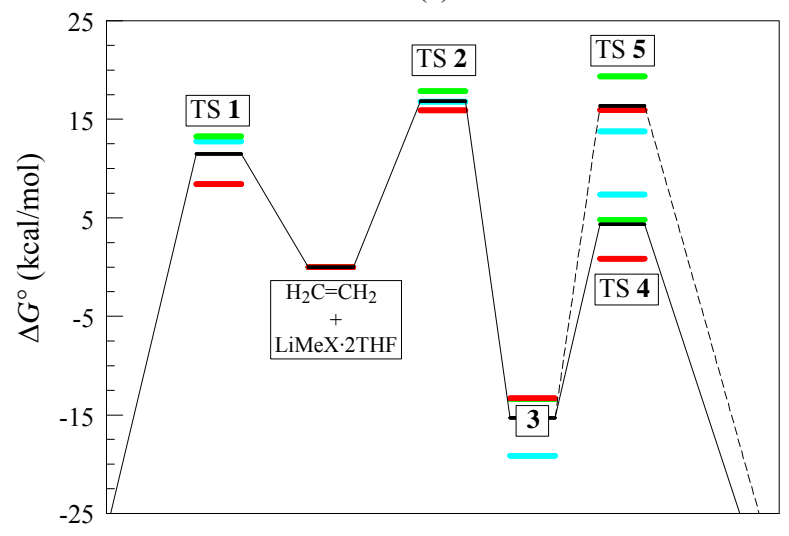

(b)

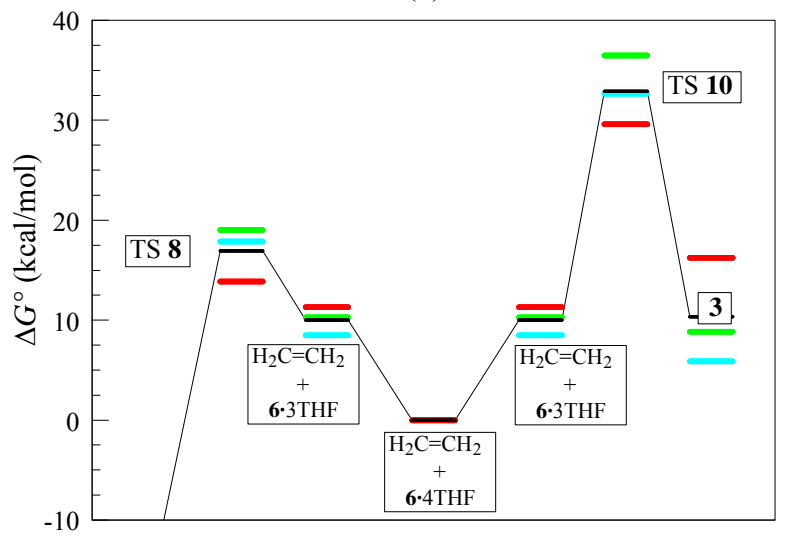

Figure 9. MP2 free energy profiles of the reactions of the (a) THF-solvated monomer and (b) dimer 6 with ethylene. The energy levels are color-coded based on $\mathrm{X}$ : blue $(\mathrm{F})$, green $(\mathrm{Cl})$, and red $(\mathrm{Br})$. The lines connect the average energy of the three derivatives of each species. All energies are relative to the reactants. For clarity, the products LiX + cyclopropane, which are at very large negative values, are not shown. 

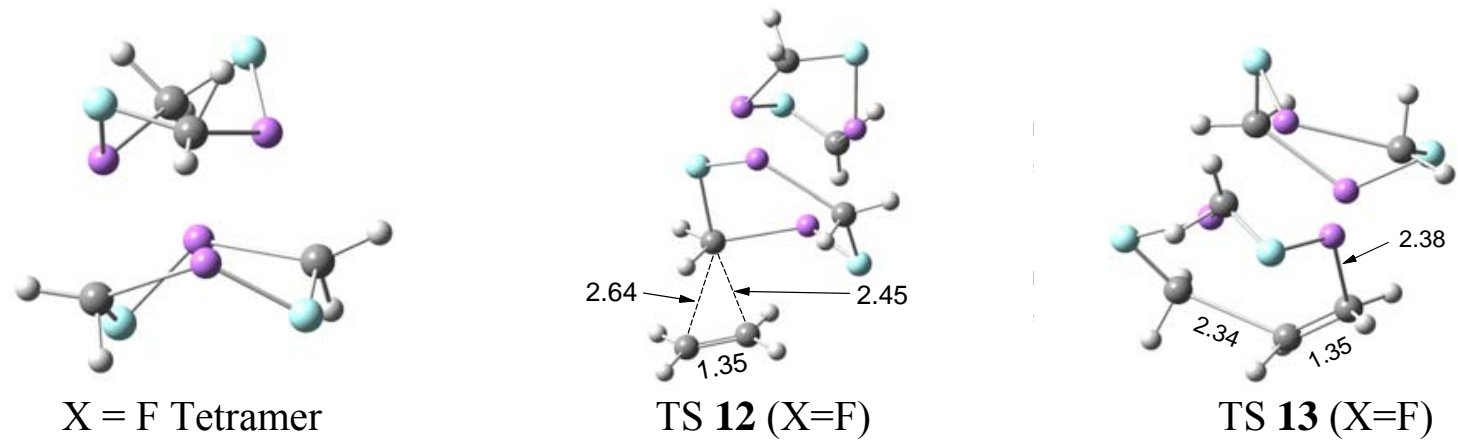

Figure 10. The MP2/6-31+G(d) structures of the tetramer, the transition state for the concerted (TS 12) and stepwise (TS 13) reactions for the case $X=F$. 


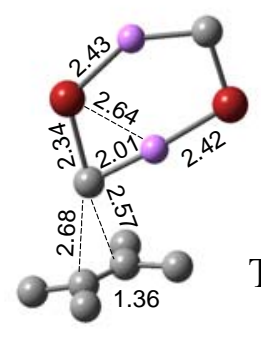

TS 14
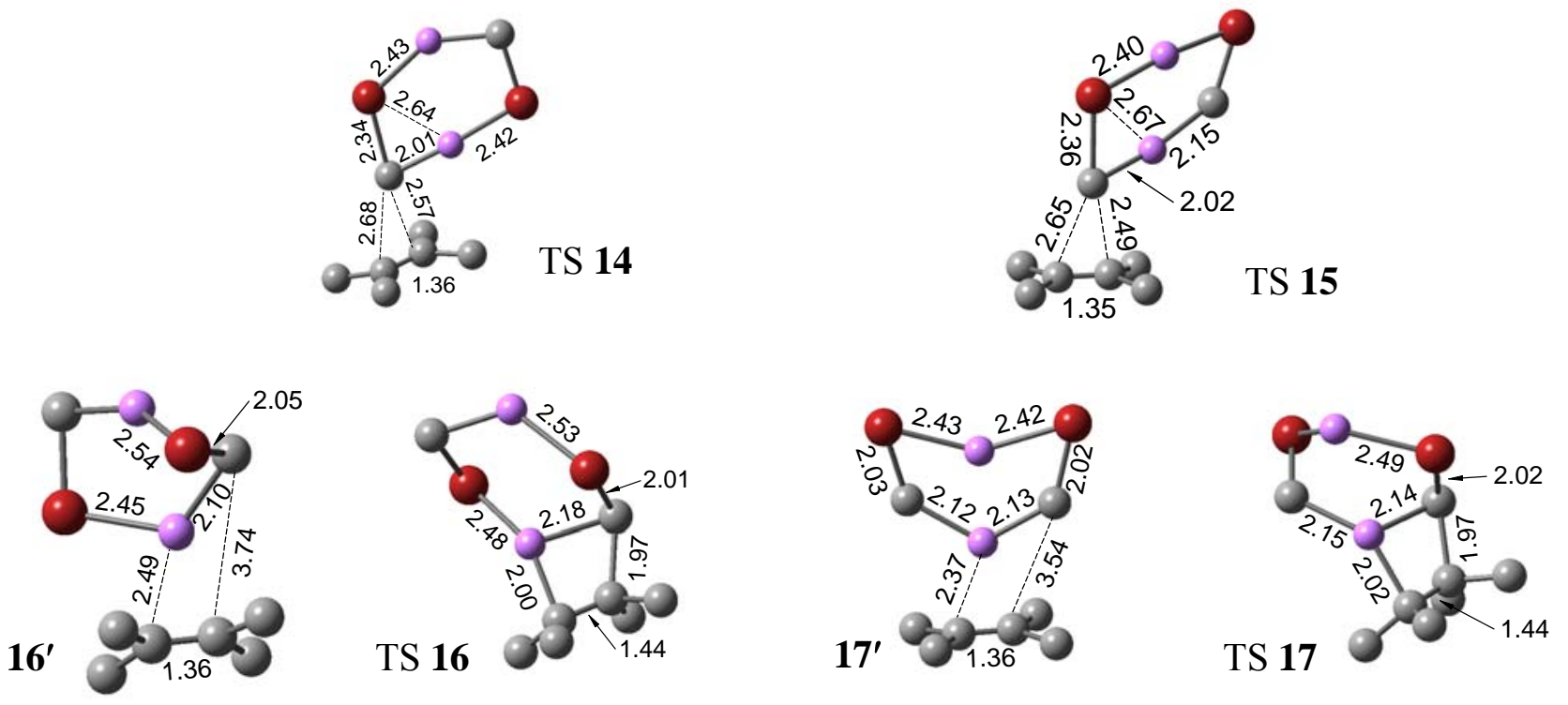

Figure 11. Upper panels: The MP2/6-31+G(d) transition states for the concerted reactions of dimer 6 (TS 14) and dimer 7 (TS 15) with 2,3-dimethylbutene for the case $\mathrm{X}=\mathrm{Br}$. Distances are in Angstroms. Lower panels: The MP2/6-31+G(d) structures of the pre-reactive complex 16' and TS $\mathbf{1 6}$ for dimer $\mathbf{6}$, and the pre-reactive complex $\mathbf{1 7}$ ' and TS 17 for dimer $\mathbf{7}$ for the stepwise reactions with 2,3-dimethylbutene for the case $\mathrm{X}=\mathrm{Br}$. Hydrogens are not shown for clarity. 

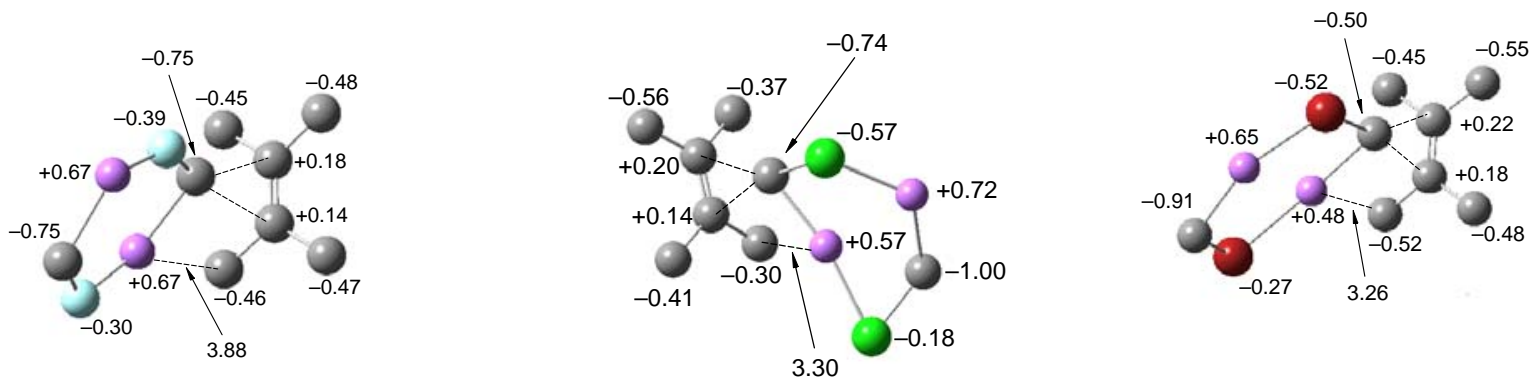

TS 14
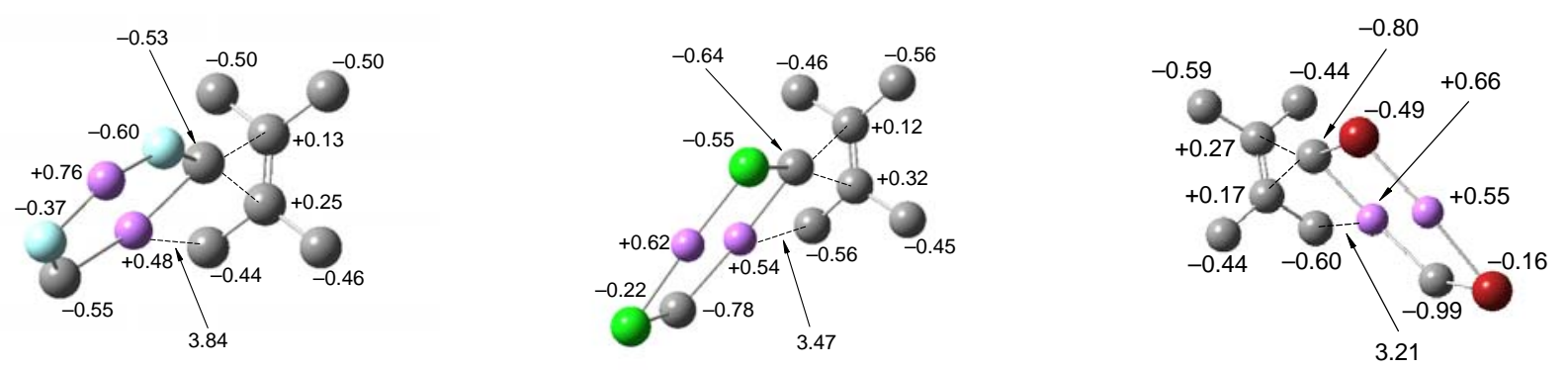

TS 15

Figure 12. MP2/6-31+G(d) structures of TS 14 (top row) and TS 15 (bottom row) showing Merz-Singh-Kollman charges and Li-C distances in Angstroms. Left: $\mathrm{LiCH}_{2} \mathrm{~F}$; Center: $\mathrm{LiCH}_{2} \mathrm{Cl}$; Right: $\mathrm{LiCH}_{2} \mathrm{Br}$. The stronger interaction in TS $\mathbf{1 5}$ for $\mathrm{X}=\mathrm{Br}$ leads to a weakly bound pre-reactive complex in the intrinsic reaction coordinate and a negative reaction barrier relative to reactants. 


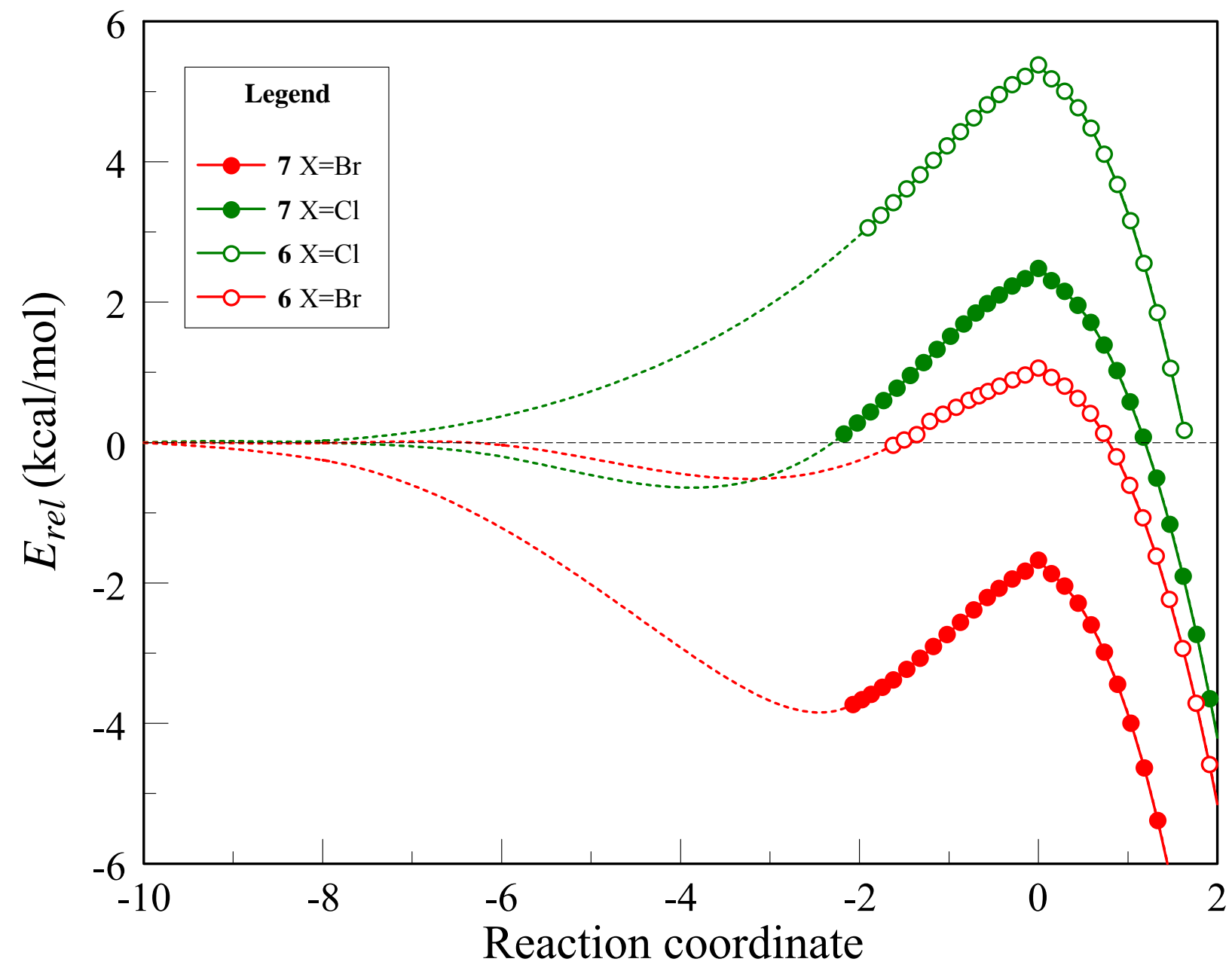

Figure 13. MP2/6-31+G(d) IRC's in (amu) ${ }^{1 / 2}$ bohr for dimers 6 and 7 for $\mathrm{X}=\mathrm{Cl}$ and $\mathrm{Br}$ reacting with dimethylbutene. The symbols connected by solid lines indicate the extent to which IRC calculations could be converged. The dashed lines are "physically reasonable" spline interpolations constrained to reach zero energy at -10 . The zero of the energy axis represents the reactants at infinite separation. 


\section{Cyclopropanation Reactions of Halomethyllithium Carbenoids: A Computational Study of the Effects of Aggregation and Solvation}

\section{L.M. Pratt, P. T. T. Trần, N. V. Nguỹên, and B. Ramachandran}

Computational results are presented to support experimental evidence that cyclopropanation reactions of halomethyllithium carbenoids with ethylene and dimethylbutene occur through the concerted (methylene transfer) pathway rather than the alternate stepwise (carbometalation) pathway.

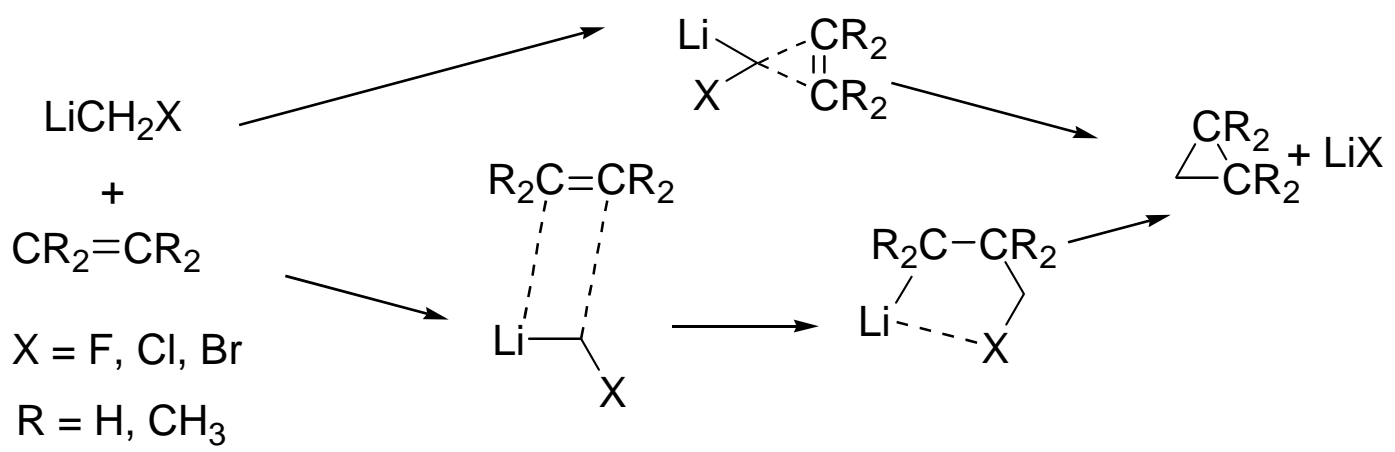

